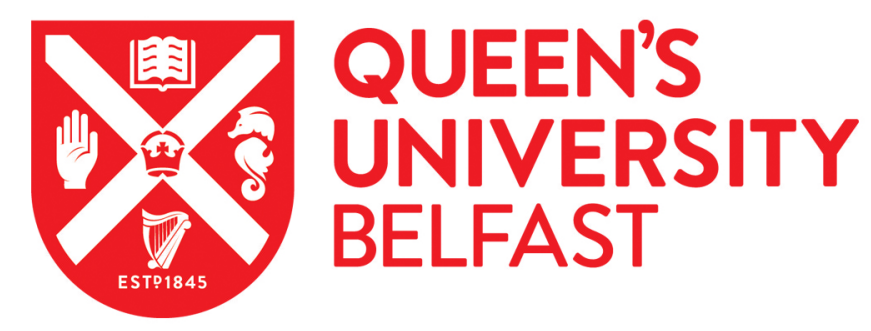

\title{
Mobile Phones and Contact Arrangements for Children Living in Care
}

MacDonald, G., Kelly, G., Robinson, C., \& Higgins, K. (2014). Mobile Phones and Contact Arrangements for Children Living in Care. Queens University Belfast.

\section{Document Version:}

Publisher's PDF, also known as Version of record

\section{Queen's University Belfast - Research Portal:}

Link to publication record in Queen's University Belfast Research Portal

\section{Publisher rights}

Copyright 2014 Queen's University Belfast.

\section{General rights}

Copyright for the publications made accessible via the Queen's University Belfast Research Portal is retained by the author(s) and / or other copyright owners and it is a condition of accessing these publications that users recognise and abide by the legal requirements associated with these rights.

Take down policy

The Research Portal is Queen's institutional repository that provides access to Queen's research output. Every effort has been made to ensure that content in the Research Portal does not infringe any person's rights, or applicable UK laws. If you discover content in the Research Portal that you believe breaches copyright or violates any law, please contact openaccess@qub.ac.uk. 


\section{Mobile phones and contact}

arrangements for children living in

\section{care}

\section{INSTITUTE OF CHILD CARE RSEARCH}

November 2014 

Mobile phones and contact arrangements for children living in care

\title{
MOBILE PHONES AND CONTACT ARRANGEMENTS FOR CHILDREN LIVING IN CARE
}

\author{
AUTHORS \\ GERALDINE MACDONALD \\ GRACE KELLY \\ CLIVE ROBINSON \\ KATHRYN HIGGINS
}


Mobile phones and contact arrangements for children living in care 
Mobile phones and contact arrangements for children living in care

\section{TABLE OF CONTENTS}

AUTHORS

TABLE OF CONTENTS

iii

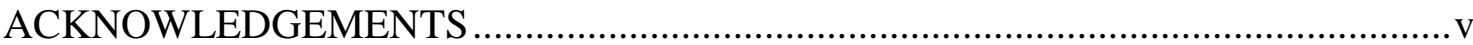

MOBILE PHONES AND CONTACT ARRANGEMENTS FOR CHILDREN LIVING

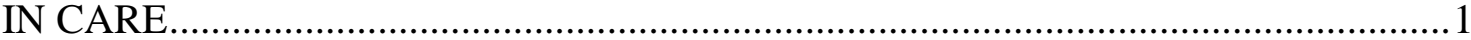

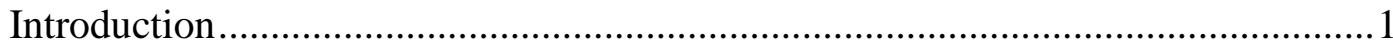

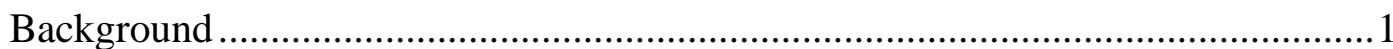

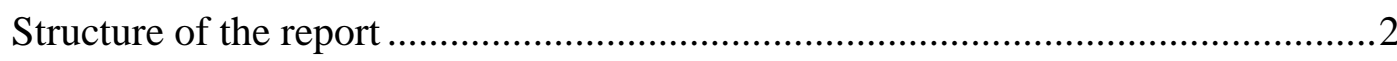

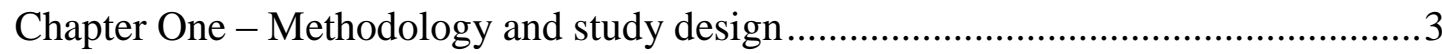

Interviews with key informants - policy level.................................................. 3

Interviews with care home managers - managerial level .....................................3

Postal questionnaire-based surveys with foster carers ......................................... 4

Postal questionnaire survey of young people living in foster care ........................ 4

Postal survey of children and young people living in residential care ....................5

Additional data from questions asked via the 'Mind Your Health: The physical and mental health of looked-after children and young people in Northern Ireland' ......5

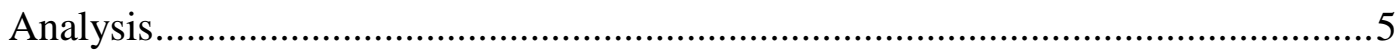

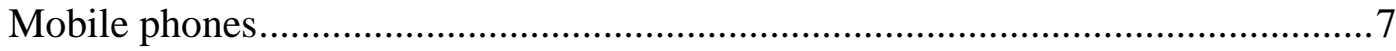

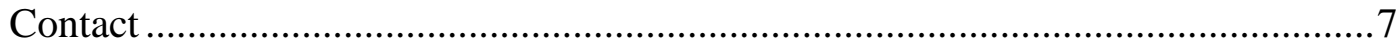

Mobile phones, children in care and contact ......................................................... 8

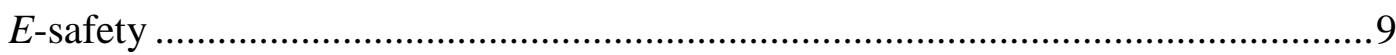

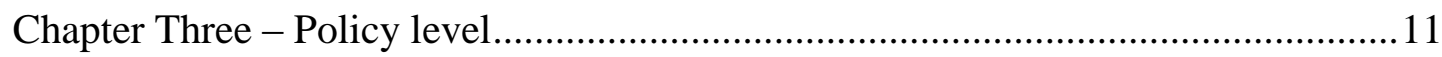

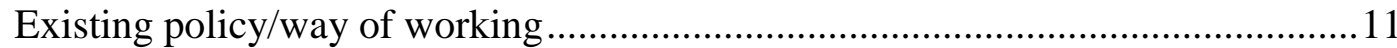

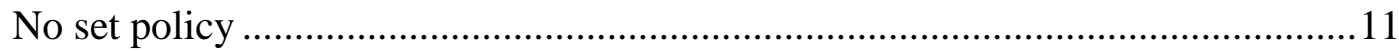

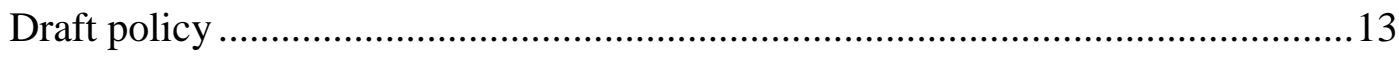

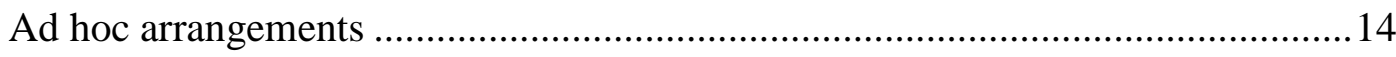

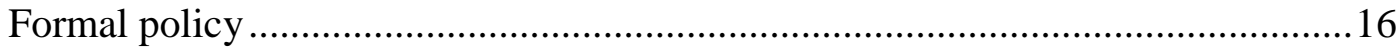

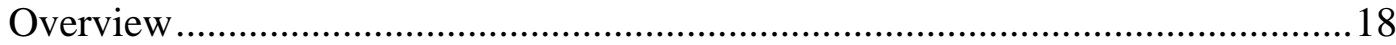

Chapter Four - Managerial level ........................................................................... 19

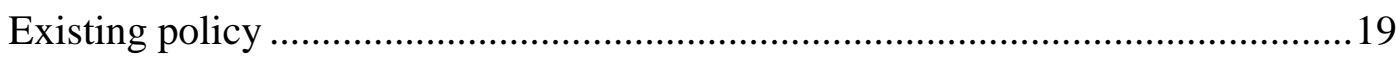

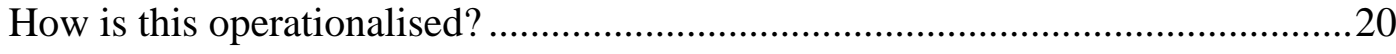

Balancing the advantages and disadvantages of mobile phone use ........................20 
Mobile phones and contact arrangements for children living in care

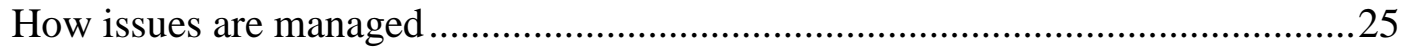

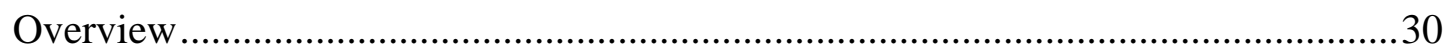

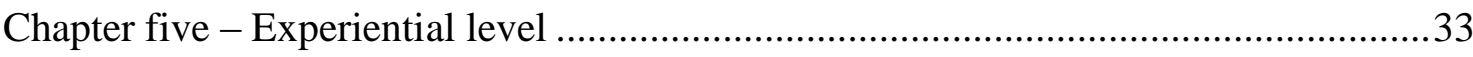

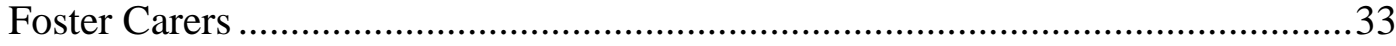

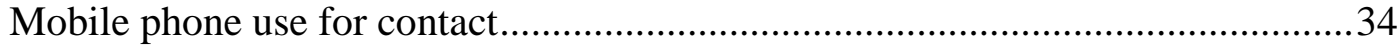

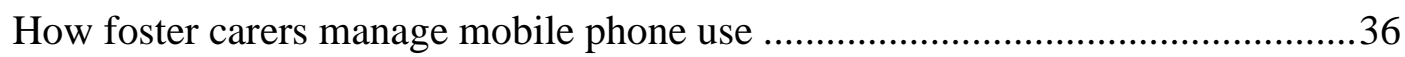

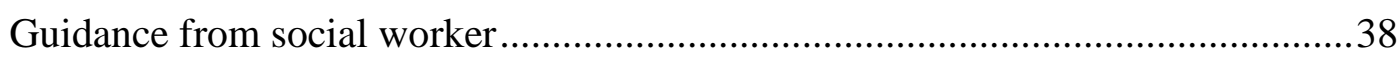

Children and young people living in foster care .....................................................38

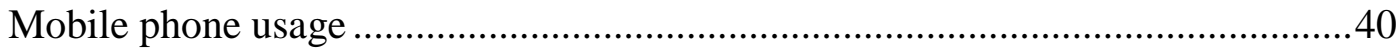

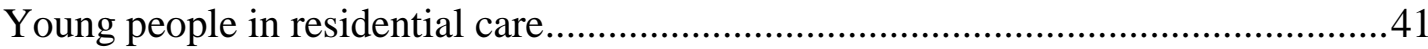

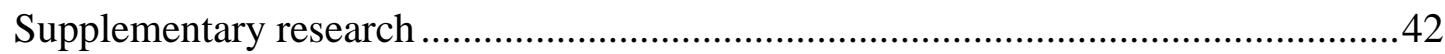

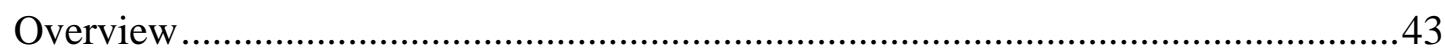

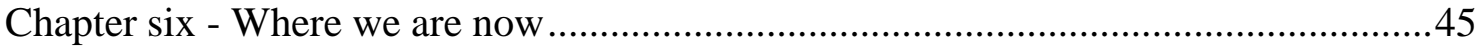

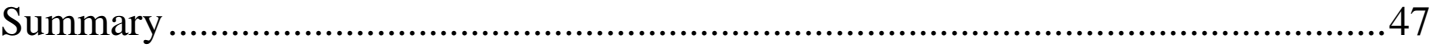

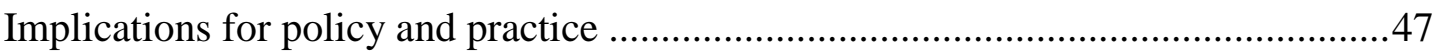

Implications for research and research governance ............................................48

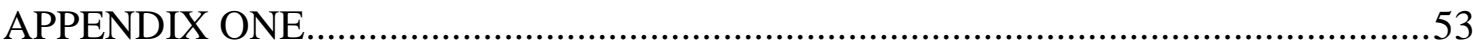

Difficulties encountered/lessons learned ..............................................................53

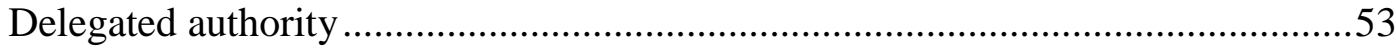

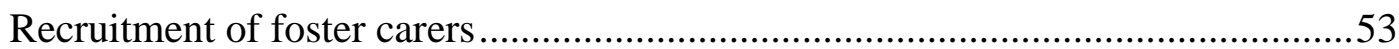

Recruitment of children and young people living in foster care...........................54

Recruitment of children and young people living in residential care ....................54

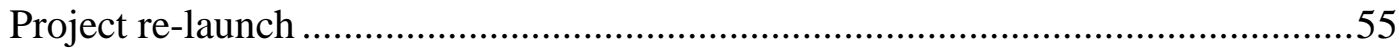

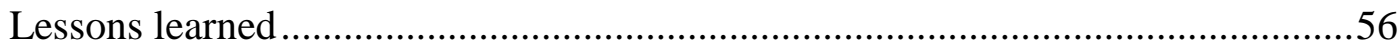

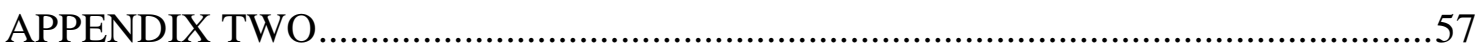

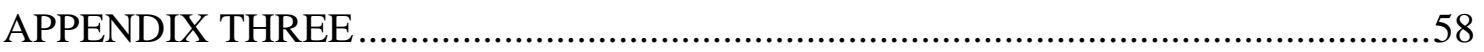


Mobile phones and contact arrangements for children living in care

\section{ACKNOWLEDGEMENTS}

We are indebted to many people for their assistance with this very challenging study.

At the outset the study benefited from the advice of members of the study's Professional Advisory Group. They reviewed the proposed research methods and processes and provided on-going advice, particularly in the early stages of the study. Members included Michael Murray from the South Eastern Health and Social Care Trust; Kath Lewis, Phyllis Elwood and Margaret Kelly from the Fostering Network; Vivian McConvey and Alicia Toal from VOYPIC, Kath Maguire from RQIA; Deborah Lyness of Youth Justice Agency; Patricia Nicholl from the DHSSPS; Jonathan Rose from OFCOM; Helen Beckett from Barnardo's and Koulla Yiasouma and Dearbhla Holohan from Include Youth.

At the finish line, our appreciation goes to a number of key personnel within the children's policy and practice domain for reading and commenting on earlier drafts of this report. These include Margaret Kelly and Kathleen Toner from the Fostering Network; Kim Wilson from the Guardian ad Litem Agency; David Bickerstaff (Health and Social Care Board), Emma Greer, David Hamilton, Jacqui McGarvey, Lorraine Noade and Anne Walsh from the South Eastern Trust; Hilary Walker from the Belfast Trust and Ian Allan from the Department for Health, Social Services and Public Safety. Their contribution both improved and shaped this final report. Whilst it is invidious to single out individuals, the contributions of Anne McGlade and Kim Wilson deserve particular note.

We are also grateful to Professor Bernadette Hannigan and her team at the HSC Research \& Development Division of the Public Health Agency. Their immense understanding of the problems that arose in seeking Trust Approval, and some additional funding, helped us complete this study.

Finally, our thanks go to every young person and their carer who agreed to take part in this study. Their participation has helped to further our knowledge in this area and makes a valuable contribution to the practical relevance of the overall findings. 
Mobile phones and contact arrangements for children living in care 


\section{MOBILE PHONES AND CONTACT ARRANGEMENTS FOR CHILDREN LIVING IN CARE}

\section{Introduction}

This study investigated the use of mobile phones by children in foster care and residential homes in relation to contact between them and their family and friends. The study considered the perspectives of looked-after children and young people, their carers and other key stakeholders.

Three research questions were posed:

1. What role do mobile phones play in maintaining contact between children and young people in care and their families and friends?

2. How do other stakeholders perceive that contact? (Do they view mobile phones as promoting good contact, contributing towards placement stability and generally enhancing outcomes for children? Or do they think that access to mobile phones undermine formally agreed patterns of contact, contribute to unintended consequences (good or bad) and/or undermine placement stability?)

3. What approaches do participants find effective in leveraging the potential benefits of mobile phones as a means of maintaining contact with family and friends, and what do they think works in minimising any adverse consequences when contact is thought best provided on a minimal basis or is not deemed to be in a child's best interest?

\section{Background}

This research study had its origins in the concerns of those working in the policy and practice community in Northern Ireland. In 2010, those working with children in care homes and in foster care highlighted the significant challenges they were facing with regard to use of mobile phones by young people. At that time, we were unable to evidence any existing research, government report, or policy document that specifically examined the use of mobile phones by children in care, and how this influenced issue of contacts between them, their family and friends. The existing literature was focused on the interaction between technology and child protection issues, specifically the use of the internet and child mental health.

Advances in mobile phone technology have been considerable since the study received ethical approval in 2011. The increasing accessibility of the internet has intensified the concentration on 'e-safety' and child protection (for example, the 2014 report of the Safeguarding Board for NI lists the growing number of key UK and international organisations with an e-safety remit). These concerns are reinforced by the ways in which research is reporting in the media: for example, the study carried out by the mental health charity Young Minds, published on Safer Internet Day (11 February 2014), was reported by BBC 1 News Beat programme as 'Mobile porn access 'damaging' children and Teenagers'. 
As evidenced by campaigning agencies for children in care (see for example Fursland, $2010 \mathrm{a} ; 2010 \mathrm{~b}$; 2011), the impact on contact arrangements of mobile phone use by lookedafter children remains a concern. This study is one of the first to explore the issue in depth. It highlights both the advantages and disadvantages of this type of contact for placement stability from the perspective of carers and senior managers in social care. These data are augmented by the views of young people themselves on the role mobile phones play in relation to contact with birth family members.

Research with children and young people, particularly vulnerable young people in care, involves major commitments, by all parties, to ensure ethical considerations are carried out to the highest professional standards. The Institute of Child Care Research has a wellestablished track record of research with looked-after children, and enjoys solid relationships with the Health and Social Care Trusts as a result. Nonetheless, the research process in this case encountered major difficulties that resulted in a smaller than planned sample and a delay in reporting.

This has not detracted from the relevance of the main findings. Moreover, we were able to supplement the data from this study with data from an analysis of a small number of questions relating to mobile phone use, incorporated within an ongoing study conducted within the Institute and funded by the Office of the First Minister and Deputy First Minister.

The major difficulties encountered and the lessons learned are significant findings in themselves, particularly relevant to all those involved in promoting the best practice in research. The main complications and challenges encountered are detailed separately, in Appendix one. Detailed coverage of these issues and the questions posed as a result of the experience will be outlined in a follow-up report.

\section{Structure of the report}

An overview of the methodology is given in chapter one. A synopsis of relevant literature, which situates the research in context, is set out in chapter two. Chapter three presents the evidence of key stakeholders on how the issue of mobile phone use was approached in terms of contact, and the way in which this was articulated at organisational level.

Chapter four focuses on how care home managers handled the matter of mobile phone use for contact. Chapter five analyses how mobile phone contact between the young person and birth family is experienced, both from the perspective of the foster carer and the young people themselves. The main focus is on the extent to which mobile phone contact enhances contact; causes or exacerbates problems in the placement and/or for the young person, and what problems, if any, carers have in monitoring and supervising this form of contact. Findings are complemented by analysis of mobile phone related questions from a current study looking at the health of looked-after children and young people. The report concludes, in chapter six, with an update of where we are now, in terms of available policy guidance on the use of mobile phone for contact, either at regional level, Board level or at Trust level. It sets out the principal issues relevant to contact arrangements for children living in care. 


\section{CHAPTER ONE - METHODOLOGY AND STUDY DESIGN}

\section{Introduction}

The original study design incorporated two phases, each with seven steps (see Appendix two).

Phase one involved postal surveys and structured interviews. It was designed to establish baseline data, map existing policy and practice, and identify the core issues relating to young people's use of mobile phones as a means of maintaining contact with family and friends.

Phase two aimed to explore, in depth, the role and meaning of mobile phones for children in care, from the perspective of the young people themselves (recruited through the postal survey). The design and development was informed by the Professional Advisory Group associated with this study, in conjunction with input from a group of parents from the Fostering Network and five Trust Collaborators appointed by each individual Health and Social Care Trust.

The major difficulties we encountered made it impossible to complete Phase two, and this report is therefore based solely on phase one.

\section{Interviews with key informants - policy level}

Qualitative interviews were conducted with eight key stakeholders with particular roles and responsibilities for regional policy, governance and inspection from within the Health and Social Care Board, the Health and Social Care Trusts and regional children's charities.

The principal aim of these interviews was to understand how agencies approached the issue of mobile phone use in relation to contact, what were perceived to be the potential benefits and difficulties; policies and practice within foster care and residential care, and the way in which this was articulated within individual organisations' procedures.

In brief, we wanted to understand the origins of organisational policies and practice, and the extent to which these had been guided by regional policies, or alternatively, whether current strategies and practices had evolved through the need to meet individual specific circumstances, possibly in the absence of regional policy and guidance.

\section{Interviews with care home managers - managerial level}

Qualitative interviews were also carried out with 20 care home managers across Trust areas. The interview covered: the extent of mobile phone ownership; the role that mobile phones were thought to play in relation to contact with family and friends and their relationship to other forms of communication; the perceived benefits and problems of mobile phones; and the general approach taken to policy and practice within the home; how staff monitored use, managed difficulties and so on.

In order to lessen the data burden on managers of the oral interview, respondents were asked in the written invitation to fill in a short questionnaire and to forward copies of 
Mobile phones and contact arrangements for children living in care

policies to the research team. Interviews were held at times that suited managers and were constructed so as to take no more than 20 minutes on average to complete.

\section{Postal questionnaire-based surveys with foster carers}

Foster carers who cared for children over the age of 10 were sent an information pack containing a letter of invitation, an overview of the study, a questionnaire and a pre-paid envelope. Foster carers were asked to indicate their consent to participation by signing the relevant section at the start of the questionnaire. Information packs were distributed by the Trust Collaborators (TCs), who used Social Services Care Administrative Records Environment (SOSCARE) data to identify the population of interest. This process took longer than anticipated as accurate contact details of foster carers and the social work teams to which they were attached, was not held centrally. In addition, SOSCARE data in quite a number of cases was out of date and/or inaccurate.

The first sweep of 841 foster carers yielded only 76 responses. Given the difficulties we had encountered in distributing information about the study, it was not deemed practical to ask the HSC Trusts to send out reminder letters. In order to increase the number of responses from Foster Carers, the Fostering Network agreed to distribute a follow-up reminder letter. The research team supplied prepared packs and return envelopes, and the Fostering Network addressed and posted the documents from their offices in January 2012. The questionnaire was also made available on-line. This increased the number of returned questionnaires by a further 52, bringing the final number of completed questionnaires to 128 .

\section{Postal questionnaire survey of young people living in foster care}

The TC for each HSC Trust used SOSCARE data to identify children aged 10 to 16 and those 17 and over, living in foster care in the Trust. The senior social worker for each child was forwarded an information pack containing a cover letter, an overview of the study and an information pack for the young person containing study information, questionnaire and pre-paid return envelope. For each eligible young person, the senior social worker assessed their capacity to give their consent, following a three step 'Capacity to Consent' Protocol. This comprised i) assessing the young person's ability to understand the study; ii) determining the appropriateness of contacting the young person at that time, and iii) gaining either birth parent consent (for those aged $10-16$ ) or birth parent assent (for those aged 17 years and over).

The young people's questionnaires focused on how, where and when they used their phones, and who they phoned; what they perceived as the benefits, particularly in relation to contacting their family and friends; what problems they had experienced, if any, from unwanted calls; confiscation of phones etc.; how their phones helped or hindered their life away from their family of origin.

Problems in relation to the SOSCARE data not being up-to-date, the 'Capacity to Consent' process (with social workers as gatekeepers), and the requirement to gain birth parent consent/assent combined to elicit another low response rate $(n=83 / 843)$. 
Mobile phones and contact arrangements for children living in care

\section{Postal survey of children and young people living in residential care}

Using SOSCARE data, the TC for each HSC Trust identified children aged 10 to 16 who were living in one of their residential care homes. The process described above was again followed, with the senior social worker having responsibility for determining and facilitating access.

Questionnaires for young people in residential care covered the same issues as those for young people in foster care, whilst reflecting their different contexts.

Unsurprisingly, this process encountered the same difficulties mentioned above. We received only 25 completed questionnaires out of 276 distributed.

Additional data from questions asked via the 'Mind Your Health: The physical and mental health of looked-after children and young people in Northern Ireland'

This study was designed to profile the health problems experienced by looked-after children and young people in Northern Ireland. The research looks at the range of initiatives being undertaken to improve health outcomes; the barriers to implementation; their acceptability and likely impact.

At our request, three questions about young people's use of mobile phones were added to the foster carer's interview schedule. Not all respondents answered these questions or believed they were relevant to them (for example, some children were too young and did not own a mobile phone). Where applicable, analysis of these questions has been used to supplement the findings of this study and provide as comprehensive a view as possible.

\section{Analysis}

Interviews were recorded and transcribed. The interview data were analysed using a 'thematic framework' approach, which is a matrix based method for ordering and synthesising data (Richie and Lewis, 2003). The same approach was used to analyse the supplementary data from the Mind Your Health survey. The questionnaire survey data were analysed using SPSS.

The findings of this study make an important contribution to the debate about contact (see Quinton et al., 1997; Ryburn, 1999; Biehal, 2007). It identifies the potential benefits of mobile phones in enhancing placement outcomes, as well as the problems associated with it. In so doing, it makes a contribution to the development of clearly defined policies, strategies and guidance materials regarding the management of mobile phone usage by young people living in care. 
Mobile phones and contact arrangements for children living in care 


\section{CHAPTER TWO: MOBILE PHONES, CHILDREN IN CARE AND CONTACT}

\section{Mobile phones}

The almost universal ownership of mobile phones among adolescents has given rise to the concept of a 'Mobile Youth Culture', in which mobile phones are a central means of enhancing a young person's status among their peer group (Castells et al., 2007; Campbell and Park, 2008; Abeele et al., 2014). Physical characteristics, such as the brand and capability of the phone, are said to hold particular importance for young people as a way of expressing their social identity and group membership (Caronia and Caron, 2004; Walsh et al., 2009).

A number of qualitative studies document the psychological influences on mobile phone use. These include the facilitation of social inclusion, social connectedness and the enhanced feelings of belonging amongst youth (Walsh et al., 2009; Blair and Fletcher, 2011). In the context of modern family life, mobile phones make communication between parents and children easier and more accessible. Studies have shown how daily phone interaction between family members has been used to mediate a feeling of closeness (Christensen, 2009). However, the nature of the phone calls has a bearing on the quality of the relationship, with parent-initiated calls for monitoring purposes, or phoning when upset, being associated with increased conflict and lowered adolescent self-esteem (Weisskirch, 2011).

2013 data for the UK indicate how mobile phone ownership increases with a child's age - from $0 \%$ at the age of 3 to $89 \%$ for 15 year olds (Ofcom, 2013). In 2013, there was no difference by gender or socio-economic group in mobile phone ownership. However, compared to 2012, 8-11 year olds are now less likely to own a mobile phone. This is attributed to a decline in the ownership of non-smartphones ${ }^{1}$ and the increase in ownership of tablet technology. Four in ten children aged 5-15 (43\%) now have a mobile phone of some kind and three in ten (29\%) children aged 5-15 have a smartphone. Around one quarter of children aged 12- 15 (26\%) and a fifth aged 8-11 (18\%) have their own tablet computer (ibid).

Similarly, the way children and young people access on-line facilities is changing. For example, the number of children accessing the internet via a laptop or PC has decreased in the past year. Ofcom (2013) reports that the use of alternative devices for online access doubled in 2012, with tablets and smartphones the most popular devices used for accessing the internet.

\section{Contact}

For children in care, contact with their families of origin is actively promoted by the Children Act 1989 and its equivalent in Northern Ireland, the Children (NI) Order 1995.

\footnotetext{
${ }^{1}$ Ofcom describes a smartphone thus: 'A smartphone is a phone on which you can easily access emails, download apps/ applications and other files, as well as view websites and generally surf the internet/ go online' (2013: 25).
} 
Though rarely used under the provisions of the Adoption Act 1976, it is an increasingly important consideration for these children too (Quinton et al., 1997; Neil et al., 2003). Contact is thought to benefit young people in care in a number of ways. Young people who are removed from their parents experience considerable loss, distress, and lack of control over their own lives upon entering care (Neil et al., 2003; Mullan et al., 2007). Contact enables young people to maintain emotional ties to people that matter to them, providing them with family support and access to people who are uniquely placed to answer personal questions (Little et al., 2005; Moyers et al., 2006). Young people themselves place particular significance on contact (Mullan et al., 2007).

For some children, however, contact can be unreliable and it can have unintended adverse consequences (Macaskill 2002; Beek and Schofield 2004; Wilson et al., 2004). Unrestricted or problematic contact can undermine the stability of placements (Sinclair, 2005). Moyers and her colleagues found that $37 \%$ of the children they interviewed were affected by unreliable contact, with over half considered by their foster parents to be having inappropriate contacts (Moyers et al., 2006). These authors concluded that, where there has been a history of abuse, disruption in placement can be significantly reduced when contact with family members is reduced or forbidden (see also Neil and Howe 2004). Their study also demonstrates that, even when contact is difficult, thoughtful assessment and careful planning by social workers can, in some cases, lead to improvements. This finding is especially important for adolescents, who are all too often left to sort things out for themselves (see also Sinclair 2005).

Focusing on the perspectives of foster parents and social workers in one Health and Social Care Trust in Northern Ireland, Taylor and McQuillan (2014) found contact to be the second-highest ranking issue (after child behaviour) impacting on placement disruption in non-kinship foster care placements, especially for children older than 12 years. In their study $19 \%$ of field social workers and $41 \%$ of foster carers said that children were having unauthorised direct contact, which the majority saw as negative. The authors considered this finding particularly important in the context that there may be an expectation that adolescents take more control over their own contact arrangements (2014: 14).

\section{Mobile phones, children in care and contact}

The opportunities and challenges presented by social networking for adoptive parents and adoption professionals are highlighted in Fursland (2010a, 2010b). For instance, the emotionally charged matter of tracing birth family members through social networking sites and issues of privacy in a digital world are significant challenges. The author notes how the complexity of the challenges makes it difficult to provide definitive guidance, and makes the case for training for adopters and adoption professionals. The need for such training is reiterated in a 2013 study of adopter's experience of unplanned birth family contact (MacDonald and McSherry, 2013).

For children and young people in foster care, where contact with their birth families is actively promoted, the facilitation of 'on demand' contact via mobile phone presents its own risks and opportunities. For example, whilst contact through mobile phone or texting makes it easier for young people to keep in touch with extended family members, this 
unregulated contact also has the potential to put at risk the wellbeing of the child and the stability of his or her placement (Fursland, 2011).

The risks and challenges mean foster carers and child care professionals have a significant role to play in managing such situations, and they need to be able to respond in the most informed way possible. Livingstone and Haddon (2009) draw positive correlations between greater use of online technology and greater risk. They further suggest that children and young people who are vulnerable offline (that is, children who lack adequate social and parental support and who may be already known to child protection services) may also be more vulnerable online. The perceived link between children 'at risk' offline and increased risk online has led some to call for special attention to be paid to children 'at risk' in relation to social networking activities (Livingstone and Helsper, 2007, Valkenburg and Peter, 2007).

Livingstone and Brake (2010) conclude that balancing opportunities and risk should be viewed differently for 'at risk' children, where 'greater monitoring or restrictions may be legitimate' compared with children not deemed at risk (2010: 80). However, as pointed out by Ballantyne et al. (2010), while it is important to acknowledge the possibly higher risks for looked-after children, and the need for caution on the part of corporate parents, greater monitoring and surveillance can often be counter-productive. Some methods of management - restricted access to, or confiscation of mobile phones - also raise issues for children's rights, namely their right to be free from arbitrary interference in their privacy (UNCRC Article 16).

Ballantyne et al. (2010) advocate the advice given by the Scottish Government (2008) to corporate parents. This stresses the importance of children and young people learning how to take risks and being responsible for themselves and their behaviour. It also stresses the need for child care professionals, particularly senior managers, to strike a balance between protection and preventing young people developing essential life skills (2008: 75).

\section{E-safety}

Widespread use of the internet, and mobile devices used to access the internet, has resulted in a growing number of organisations delivering messages on the interaction between modern technology and child protection issues. A recent assessment of the nature of $e$-safety messages by the National Children's Bureau $(2014)^{2}$ reported that the most common themes of $e$-safety messages in Northern Ireland were: using mobile phones, cyber bullying, use of privacy and personal information, and 'sexting'. However, an assessment of the quality of the information proved difficult as much of the work on $e$-safety messaging was not apparent or accessible on the websites of delivering organisations (2014: 8). The only area where enough information existed to carry out a comparative analysis of the quality of the information available was cyber bullying.

\footnotetext{
2 The SBNI (2014) report describes e-safety as: "E-safety or electronic safety is about utilising electronic devices or e-technologies in a safe and responsible way. It is mainly concerned with the safeguarding of children and young people in the digital world and educating them so they feel safe when accessing etechnologies." [NCB NI definition]
} 
Mobile phones and contact arrangements for children living in care

A survey focusing on the training needs within health, education and children's services (on behalf of the Marie Collins Foundation) revealed a gap in the confidence and capability of professionals to meet the needs of children harmed on-line (Bond and Agnew, 2014). Amongst the examples of concern experienced by professionals, problematic contact was cited as an important issue. Concerns included birth family members being contacted through Facebook and initiated telephone contact without carer/social worker support. The survey findings reported an ad hoc response by professionals which does not represent current best practice.

The fact that the issue of contact featured, albeit negatively, underlines the fact that online safety concerns and child protection issues are not discrete from the matter of contact. 


\section{CHAPTER THREE: POLICY LEVEL}

This chapter presents a picture of the main issues perceived at policy level and draws out common approaches to the management of such issues. In exposing the perceived advantages and disadvantages of this type of communication, it highlights the challenges involved in reaching an appropriate balance between child protection issues and promoting children's rights.

\section{Existing policy/way of working}

Eight key informants contributed to this study. The interviews were carried out between April and November 2011. At that time, we were unable to locate any overarching policy or guidance, at departmental regional level, specifically on the use of mobile phone contact arrangements for looked-after children and young people. It appeared that none existed, so we sought to identify how issues were managed in the absence of official guidance.

Interviewees were first asked whether specific policies relating to mobile phone use existed within their organisation. From the small number of respondents, four different categories of practice could be identified. This ranged from having no formal written policy procedures to having a formalised contract between the young person and the organisation. This is set out below in table 1 followed by a detailed explanation of each separate category:

Table 1: Existing procedure at policy level

\begin{tabular}{|c|c|c|c|}
\hline Type of practice & Description & Organisation/s & $\begin{array}{c}\mathbf{N} \\
\text { Respondents }\end{array}$ \\
\hline No set policy & Lack of any guidelines & $\begin{array}{l}\text { Charity providing services to } \\
\text { vulnerable children and young } \\
\text { people }\end{array}$ & 2 \\
\hline Draft policy & $\begin{array}{l}\text { Mostly relating to staff } \\
\text { policy }\end{array}$ & $\begin{array}{l}\text { Charity providing services to } \\
\text { vulnerable children, young people, } \\
\text { adults and families }\end{array}$ & 2 \\
\hline $\begin{array}{l}\text { Ad hoc } \\
\text { arrangements }\end{array}$ & $\begin{array}{l}\text { Deals with a situation as } \\
\text { and when it arises }\end{array}$ & Health and Social care Trust areas & 3 \\
\hline Formal policy & $\begin{array}{l}\text { Signed contract between } \\
\text { the organisation and the } \\
\text { young person }\end{array}$ & $\begin{array}{l}\text { Charity providing services to } \\
\text { vulnerable children and young } \\
\text { people }\end{array}$ & 1 \\
\hline
\end{tabular}

\section{No set policy}

This represents the views of two stakeholders. In this situation, the agency had no formal written procedure on the use of mobile phones for contact arrangements for children and/or young people in care. While certain guidelines were in place, they were mainly relating to general internet safety guides and did not focus on mobile phone use per se. Those interviewed noted that this was a situation that needed to change swiftly, because the issue of mobile phone use was being raised during training sessions for foster carers 
Mobile phones and contact arrangements for children living in care

and social workers. In addition, they reported that approaches had already been made by social workers and personnel from the medical and legal professions looking for guidance.

'There isn't a lot of policy and practice guidelines around. We are getting asked questions by social workers and even medical practitioners...so they are beginning to look at the issues. I would say also the legal personnel. People are looking for guidance and ways of managing.'

There was an acknowledgement that, while internet safety remains a pivotal matter, issues have progressed from promoting safety guidelines for on-line use for young people, to consideration of more subtle and complex issues.

For example, in terms of the assessment of potential carers, informants pointed to developments in England and Wales which were focusing on the use by foster carers of social networking sites and the internet in general. Attention was drawn to the potential risks posed by having extensive information about a foster carer's family (or potential foster carer family) publically available on networking websites. Interviewees placed strong emphasis on the training needs of carers (and potential carers) in how to use this type of social media properly and safely. This was an interesting point because the focus here was on the adult carer's practices and not the young persons.

Interviews considered the fact that mobile phone use did not feature strongly in existing preparation arrangements for foster carers as a lost opportunity. When asked if the issue of mobile phone use for contact should be brought within the realms of a more formally agreed process, one informant said 'I just don't see how they cannot do it'.

Following on from the shift in focus from the young person's behaviour to the adult carer behaviour, an important issue emerged. This concerned the uncertainty surrounding the exact specifications of formal contact arrangements via mobile phones between the young person in care and their key social worker. From the experience of the key informants, a lot of social workers used a mobile phone to keep in contact with the young person in their care. This raises the question as to what extent a text message or a telephone call from a mobile phone complies with statutory expectations of contact between social workers and looked-after children. It also points to a risk that overworked social workers may substitute a mobile phone contact for a face to face contact, thereby forfeiting the opportunities for counselling and social work support that face to face meetings provide, and which are important both for children in foster care and residential care. This issue was raised in the Inspection of Child Protection Services in Northern Ireland Report (DHSSPS, 2006), which found that contacts by the social workers 'were not always adequate to address the situations that arose. It was also of concern that telephone contacts and text messages were used in a number of high risk situations that would have warranted direct therapeutic intervention.' (2006: 11.25.1) Among the recommendations, the DHSSPS report stated that 'telephone calls or text messages by social workers do not become a substitute for the direct contact needed, particularly, when a child is distressed or has suffered a traumatic experience' (2006: 11.26).

The consensus from the key informants was that the need for policy guidance on the use of mobile phone for contact was self-evident. The difficulty was trying to develop a 
Mobile phones and contact arrangements for children living in care

policy capable of striking the right balance between, on the one hand child protection, and on the other hand, championing the rights of children. Informants were of the opinion that there was a lack of coordination between safeguarding and care planning for lookedafter children:

'It seems to me that you have to really work at bringing those two things...it's as if they're kept separately - this division between safeguarding and LAC which I think is not really sensible because just because you come into care, doesn't mean there are no more safeguarding issues. There's not a good split there between safeguarding and LAC. There needs to be more of a transfer of knowledge.'

A good example of addressing both issues emerged when one respondent talked about recent discussions with foster parents whose children had sent inappropriate images of themselves from their mobile phone. The respondent explained that the foster carers' sadness was framed in relation to their children's self-esteem issues. Even though there were known legal implications, foster carers were able to take some comfort from the stance taken by the police in ensuring that safeguarding issues were addressed, but at the same time, not criminalising the young person:

'I think the police statement on the sending of images, foster carers found that helpful because it made them less frightened...I think they found that useful.'

Trying to balance safeguarding issues and upholding children's rights at the same time was also manifest through the evident positive aspects of mobile phones, which act as a counter-balance to the negative elements of mobile phones.

In terms of the positive role that mobile phones play in the lives of children in care, maintaining a relationship with a wide family network was thought by these informants to be particularly beneficial. Especially constructive was the way it facilitated sustaining relationships with siblings and grandparents. On the other hand, it was also felt that birth families could see it as a way of keeping a closer check on a placement or what was happening in a child's life. This was perceived as posing risks to the stability of a child's placement. Numerous advantages and disadvantages were stated by all participants, but the main point to draw out here is the belief that being overly prescriptive did not present a viable option. This was illustrated in the opinion of one key informant when talking about the dangers of being overly prescriptive and the consequent risk of exacerbating difference:

'Whatever we feel about the benefits or challenges with it, I think for them, it's another difference if we don 't handle it right.'

\section{Draft policy}

In this example, a mobile phone policy had been developed by the organisation in reaction to having experienced a number of negative incidents in the past. What is different here is that the policy extended to staff as well as young people. However, at the time of interview, the policy had a heavy regulatory focus on staff practices relating primarily to 
Mobile phones and contact arrangements for children living in care

the use of personal mobile phones during working hours, health and safety issues, security and data protection, pricing and budgetary matters and the loss of Trust property.

Just a short section related to the appropriateness of work related contact use between staff and service users. Mainly, this was advice on being mindful that correspondence should be respectful. It transpired that the policy had caused some consternation among staff with subsequent trade union intervention. Consequently, the policy was rewritten a number of times and was currently in draft form. While it was the view of the respondent that the initial policy emerged from child protection issues and also a desire to protect staff, in effect it was more directed towards staff conforming to practical uses than the nature of the contact as such.

\section{Ad hoc arrangements}

Here, practice seems to have evolved in response to specific issues. According to respondents, mobile phone use was discussed during the statutory reviews undertaken of looked-after children (LAC reviews). If a concern was identified during this process, then a solution to solve that specific problem would be proposed. For instance, if mobile phone use was causing concern with a young person in foster care, the foster carers would be advised to take the phone off the young person at night time. But respondents also acknowledged this was a very difficult thing to do. An example was given of an incident the previous year where a mobile phone was removed entirely from a young person, but it was an extreme case. Besides, it proved fruitless because, as mobile phones are so cheap, it was easily replaced by the young person.

It should be pointed out that most of the discussion with respondents in this category took place with key informants who were working with young people aged 16 and over. While they were still involved in the LAC review process, they were also preparing for transition towards independent living. It was felt that, at this age, there was little opportunity or advantage in being prescriptive regarding mobile phone use. It was also felt that the residential care homes should have already covered this groundwork before the young person reached this stage. Nor did mobile phone policy feature formally within a Pathway Plan for young people aged 16 and over. As one respondent explained

'It's not something that's an issue. It's just everybody has a phone and that's just it.'

The Pathway Plan was designed very much on a case by case basis. They were described as being deliberately vague to allow for individualisation. Providing information on housing, employment and education were viewed as prerequisites for independent living. The focus in these instances was on a very practical level, involving equipping the young person with skills such as cooking and health care. Regarding the use of mobile phones, guidance was viewed in pragmatic terms such as ensuring the young person was made aware of the proper organisations to contact should help be required with specific problems.

The preference was to keep mobile phone use on the agenda through inclusion within a wider emphasis on education and training in the safe use of all types of multi-media communication, including Child Exploitation and Online Protection (CEOP) training. 
Peer educators and group work covering over-arching health issues like sexual health would include information on keeping safe and healthy on-line, as well as in more traditional arenas. This was also provided on a one-to-one basis. However, one of the main impediments to providing training was the lack of motivation on the part of young people to participate. While not universal, a lack of confidence and self-esteem, together with feelings of insecurity, was thought to have impacted negatively on young people's enthusiastic responses to training.

In addition to existing internet safety training and drugs and alcohol awareness programmes, one respondent talked about how they had made attempts to identify training needs among LAC teams, residential care home staff and social workers in their Trust area. This resulted in the development of educational materials and the organisation of training programmes. However, a lack of motivation and poor uptake of these programmes among staff was reported. Heavy caseloads and busy work schedules were thought to have contributed to the lack of interest.

'Social workers I think are just so busy prioritising stuff that this just comes down the line.'

Some frustration was discernible at the unimaginative response from one Trust's corporate response to attempts to initiate any type of innovative internet presence designed specifically for young people. The general feeling was that what was in existence was so dull, it was ineffective. This points to a gap between young people's expectations of e-technology and older people's knowledge (or interest) in this area.

Where arrangements were described as 'ad hoc', more negative views were expressed than positive. One respondent had difficulty giving any positive experiences.

'I went round the teams yesterday to get a sense of it and nobody came up with any positive experiences.'

'Where we have contact arrangements in place, where there is supervised contact between the parent and the young person - say every month - it's supervised by staff so that nothing untoward happens and nothing is said to the young person that shouldn't be said. That's what has been agreed and signed off by the courts as well. But what happens is that in a lot of cases the parent and the young person make contact with each other through mobile phones. Nobody can police that and nobody can monitor that.'

The belief here was that mobile phones facilitated a means of communication for parents to have contact with their children that they should not be having, with the potential to undermine the care placement. In one example cited by a respondent, a young person wanted more contact with their birth parent and in this instance the Trust was supportive of mobile phone contact. However, the parent did not engage with their child's desire for increased contact, resulting in the young person becoming extremely upset because they knew how easy it would have been for their parent to make contact via mobile phone. This had the effect of reinforcing the young person's sense of rejection and abandonment. 
This highlights the varied dynamics of mobile phone contact. For example, the word 'needy' was used by more than one respondent to describe some parents use of the mobile phone which caused great distress to the child. Examples were given where a young person had 60 missed calls from his mother in the course of a few hours and 30 missed calls from his father on a separate occasion. Often in these situations the mental health of the parent was a key factor. The difficulty here was trying to arrive at a solution when little or no power over how a parent used their mobile phone for contact existed. Removing or limiting the young person's use of their mobile phone, as a reaction to this, would effectively mean punishing them for events beyond their control.

The conflicting positives and negatives of mobile phones regarding contact arrangements was clearly reflected in the way bullying was used as an example of both scenarios. For example, one respondent recounted how a young person had used their phone to bully others, while another respondent believed that not having access to a mobile phone would lead to the young person being bullied.

In terms of advantages, it was felt to lessen feelings of isolation and provided a good way of communication. It kept young people in touch with extended family members. This was particularly important in Trust areas where wide geographical distances existed between a young person's placement and their family.

\section{Formal policy}

Here, policy was to develop a personalised, formal 'contract' between the young person and the agency as each individual placement was finalised. It was not specific to mobile phone contact use and covered access to the internet, Facebook and other social media sites. The agreement was adapted to match the circumstances of the young person. For example, should mobile phone use become a major concern, the terms of the personal contract would be renegotiated.

An example was given where a young person was contracted to have their phone for ten minutes every day (no explanation provided). That would be reviewed according to the individual circumstances and needs of the young person. The agreements appeared to be quite strictly imposed and monitored on a regular basis. For example, a common clause in the contract was to ban access to the mobile phone at bed time. This type of practice was unusual compared to others that we spoke to at the time, at the policy level. We believe this is reflective of the independent agency's size and regulatory authority in comparison to the Trusts organisational procedures.

This level of authoritative control gave rise to some discord among social workers. While some social workers reported themselves to be happy with this type of procedure, others were not. Some believed it impinged on children and young people's human rights. The need to reach a compromise between managing child protection issues and promoting children's rights featured strongly here. However, the stance taken by the agency seems to be more heavily weighted on the side of child protection, as evidenced in the following quote:

'Sometimes I think in the care sector we feel that it's really bad to take their phone off them. Actually all children have their phones taken off 
Mobile phones and contact arrangements for children living in care

them at times because they need taught how to use them - and these unlimited phone contracts haven't helped. At least when it was pay-asyou-go when your money run out, your money run out.'

This is not to say that children's rights were not also a major concern. This particular respondent reiterated the need for striking the right balance between the two and how this could be achieved by working on relationship building. It was felt that good relationships between the young person and the person drawing up the contract would help make the contract work. Although it still appeared that the main focus was on making the contract work independently.

The issue of 'needy parents' emerged again as an issue relating to contact. For example, the respondent explained how in some cases they had contact orders, where supervised and restricted contact has been directed by the courts, but the young person could end up having daily contact by mobile phone. This was described as almost always at the behest of the parent:

\section{'I've rarely seen children who seek their parents out, it's more the parents seek the children.'}

It was again pointed out by the respondent that officially agreed contact arrangements seldom mentioned contact by mobile phone. Even when a formal court agreement had been reached on phone contact, it almost never differentiated 'mobile' from 'landline'. Had this been stipulated in the official court order, it was felt the agency would have more power to challenge the parent for contravening the order.

Mobile phone use in general was said to be specifically useful for maintaining relationships with the wider family network. Relationships with grandparents were singled out as particularly benefiting from this form of communication. Maintaining good relations with peer groups that the young person had grown up with was another advantage. As the young person so often returns to their family eventually, mobile phone contact means that existing friendships could be recommenced when the placement ended.

The negatives were associated with improper contact and sending inappropriate photographs over the internet. This was exacerbated by the informational gap between young people and older foster carers. Young people were felt to be so adept at using all types of e-technology that it has become almost impossible to monitor use and stay one step ahead. One response from the agency to this knowledge deficit has been to seriously consider the technological training needs of potential foster carers in preparation for any future placement. But realistically, this generational knowledge chasm is presenting challenges, not just for foster carers, but for organisational personnel, as explained by the key informant:

'I grew up in a generation that I didn't really use computers and I am definitely on the back burner. I need educated.' 
Mobile phones and contact arrangements for children living in care

\section{Overview}

Among the main issues to emerge was the lack of agreed formal policy on the use of mobile phones across Trust areas. Key informants from the independent and voluntary sectors were more inclined to identify a need for specific policy or guidance than informants from the Trusts. However, respondents were aware of the difficulties involved in constructing a policy that would be meaningful across a broad range of age groups and individual circumstances. For example, the policy conditions for a younger child would not be appropriate for a 16 year old.

There were a number of common threads visible in this section of interview data: All respondents discussed the conflict between safeguarding issues and children's rights. This was most in evidence during debates on the perceived advantages and disadvantages of mobile phone arrangements for promoting family contact - with positives and negatives often counteracting each other. A lack of coordination between safeguarding and care planning was identified. This was not completely irresolvable - the police action cited earlier (to ensure that safeguarding arrangements were in place, and satisfactory, and at the same time not unnecessarily criminalising children as a first measure) - is a good point in case.

Respondents all identified a knowledge gap between young people's technological ability and that of older people. This posed difficulties for monitoring any type of sanctions or limited use as the young person's wider knowledge automatically put them at an advantage. It was also thought to be counterproductive as one respondent noted:

'When you start to police mobile phones, the relationship starts to break down so, so much'.

General online safety training, while important, appears to be thought of as an allencompassing method of education on these issues. However, it misses the complex nuances in personal interactions such as the pattern of parent-child communications - the course of which has been shown to impact both negatively and positively on a young person's sense of self-esteem (Weisskirch, 2011). The concept of the 'needy parent' arose where continuous contact was facilitated by mobile phone use. This brought to light the lack of formal agreement with the parent regarding parental phone contact, including the type of phone contact not being identified in a court order.

It was not the intention of this study to examine the issue of mobile phone use for contact between young people and social workers. However, the subject did emerge during interviews with key informants and is noted here. The main points raised involved the frequency of contact via mobile phone and the status of this type of contact between the key social worker and the young person. Knowledge about whether mobile phone contact constituted an 'official' contact was not clearly expressed. This increases the risk of possible misunderstanding and increases the danger of replacing the face to face contact needed to provide appropriate therapeutic counselling and support services. It is a situation that needs to be addressed for the protection of both young person and social worker. 


\section{CHAPTER FOUR: MANAGERIAL LEVEL}

At managerial level, analysis focused on how care home managers governed the matter of mobile phone use for contact. In the event of no existing overarching policy, we were interested in the way the issue was managed across different sites and whether there were commonalities in the way mobile phone use was experienced. We aimed to determine the way practices were formed: for instance, what was the source and basis of argument for the way issues were managed within each Trust area.

Structured telephone interviews were carried out with 20 care home managers as set out below:

Table 2: Residential care home manager interviews

\begin{tabular}{ccccc|}
$\begin{array}{c}\text { Belfast } \\
\text { HSC } \\
\text { Trust }\end{array}$ & $\begin{array}{c}\text { Northern } \\
\text { HSC } \\
\text { Trust }\end{array}$ & $\begin{array}{c}\text { South Eastern } \\
\text { HSC Trust }\end{array}$ & $\begin{array}{c}\text { Southern } \\
\text { HSC } \\
\text { Trust }\end{array}$ & $\begin{array}{c}\text { Trust } \\
\text { Trestern }\end{array}$ \\
\hline 4 & 5 & 3 & 5 & 3 \\
\hline
\end{tabular}

The first step was to determine whether or not the home had a mobile phone policy and if contact by mobile phone ever featured in agreed contact arrangements.

\section{Existing policy}

Analysis of interview data with residential care managers confirmed that no formal policy guidance existed on the use of mobile phones at this level. In some cases, there was a short reference in the home's Statement of Purpose alluding to a policy on mobile phone use. However, in most instances, this was extremely vague. In one case, there had been a very rigid and formal mobile phone policy in existence. On the basis of training in the model of therapeutic care adopted by the Trust (Children and Residential Experiences (CARE)), this policy had been over-turned by the care home manager because it was believed to be triggering bad behaviour. A less stringent policy was introduced.

In most care homes, what existed was a policy of establishing an internally written and agreed contract between the home and the young person on a set of 'house rules', including how mobile phones should be used. In a few instances, the contract was verbally agreed. Contracts were individualised and tailored to meet the specific circumstances of the young person and modified according to their perceived level of need.

The most common practice was to discuss mobile phone use on admission, alongside all other considerations. This included the young person's age, how far they were away from home, whether there were any specific reasons why they should not have contact with family, for example, in cases where family contact would be detrimental to the young person. In the majority of cases, these contractual agreements were looked upon as coming under the general ways of working of the home, and differed in relation to individual circumstances.

Some variations in the way the contracts were negotiated were evident - some care homes involved the young person in writing them, others did not. A small number involved the 
parents in drawing up the contracts, but not all. However, all contracts had room for manoeuvre, with no hard and fast rules that could not be altered

The main point here is that these contracts were, by necessity, negotiated in the absence of any regional guidelines.

All but one of the respondents reported that mobile phone use for contact arrangements did not feature in any formally agreed care plan, unless there had been a specific issue before the young person entered the home: for example, if a restriction on contact had been enforced by the police before the young person came into the care placement. One respondent said that care plans sometimes made provision for staff to contact the parents by text if there was an issue of concern. This was the only example of this practice. There was no evidence that this practice had been approved by the Trust or the implication of this has been fully explored, given the vulnerability of young people in care and the types of problems and risks that arise.

\section{How is this operationalised?}

There are two main influences which we believe are accountable for the specific way this issue was managed across different sites at this level of administration. Firstly, mobile phone use was looked at more positively by care home managers than by those at regional level. This was despite the fact they recognised the considerable disadvantages. While not universal, the general opinion was that the advantages outweighed the negatives.

Secondly, the impact of the therapeutic perspective adopted by the children's home was very much in evidence. A number of managers explicitly made reference to their specific therapeutic approach and indicated how their way of working was informed by the ethos of such an approach. For others, references were more implicit. However, with all the care home managers we interviewed, it was clear that their procedures for managing this issue were guided by therapeutic assessments. These two influences are discussed below in more detail.

\section{Balancing the advantages and disadvantages of mobile phone use}

On the negative side, the disadvantages were very significant. In particular, references to actual and perceived risks of sexual exploitation through the use of mobile phones were raised as a major concern. These included past incidents which had involved police intervention and current instances which were giving cause for concern. There was no information on how current potential risks were managed.

The 'use of a mobile phone that causes concern' has been previously identified as a risk indicator in a report which investigated the extent and nature of sexual exploitation of children and young people in Northern Ireland (Beckett, 2011). The research, carried out by Barnardo's, also reported the covert nature of communication via mobile phone and/or the internet which facilitated the sexual exploitation of children and young people. As a group, children in care were identified as being at greater risk of sexual exploitation than those not in care (2011: 96).

The main positive to emerge was the enhancement of family relationships. In this respect, mobile phone contact played a beneficial role in maintaining family contact with parents 
Mobile phones and contact arrangements for children living in care

and the wider family network. For example, heavy demand for placements often result in the child or young person being placed in a home a considerable distance from their family. Thus, the additional factors of time and travel costs can often be mitigating circumstances in limiting family access. Mobile phones were believed to be able to compensate for possible restricted contact due to geographical distances. As one respondent replied:

"Five years ago we would have thought of them [mobile phones] very negatively but they've become a very useful tool. Especially as homes can be filled and the young person might by 50 or 60 miles away from their family."

From the care home manager's viewpoint, mobile phones made it easier for some young people who, while wanting to maintain contact, did not want (or were not ready) to speak with their parent or one or other family members just yet. For some managers, text messaging was viewed as a 'bridge' which could keep lines of communication open in the meantime. Texting was also regarded as a helpful way for the young person to maintain contact with a parent who was perhaps less engaged; for example, where replying to a text sent from the young person would require less effort from the parent than a visit. The main objective here was to keep lines of communication open at all times.

The psychological and emotional comfort provided by the knowledge of having immediate family contact, if required, shaped a large part of most of our interview responses. In this respect, mobile phones helped to provide a reassurance and comfort to children who had already experienced considerable loss and distress upon entering care. It was said to make them feel still a part of their family, even though they were not living with them. This was especially important when they lived a distance away. In fact, there was a sense that a strong psychological link existed between mobile phones and the lives of young people in care.

In these scenarios, mobile phones were believed to help provide stability to existing placements through enhancing family contact and maintaining relationships. Only in two cases was there a disagreement of opinion between interviewees on such benefits. In one instance, the residential home (in question) was a short to medium term home providing care to primary aged children. In this home, the manager believed the potential for mobile phones to enhance placement stability was limited because of the young age of the children, not least because most did not own a mobile phone at that time. However, this interview took place in the later part of 2011. As indicated earlier, the most recent figures for mobile phone ownership show that four in ten children aged 5-15 (43\%) now have a mobile phone of some kind and three in ten (29\%) children aged 5-15 have a smartphone (Ofcom, 2013). We are confident the situation will have changed since then.

The second example where opinion differed was where the interviewee admitted that their lack of technological knowledge meant they did not understand the positives or know how mobile phones could enhance a placement. It was explained in this way:

"I suppose I'm not even technically minded in order to think of it in a slightly different perspective. Nä̈vely I would probably say not an 
Mobile phones and contact arrangements for children living in care

awful lot [of positives]. We're more about educating them about the dangers of it...it's more about protective work."

For this respondent, the difficulty in identifying the positives (even though it was acknowledged by the respondent as 'naïve') shifted the focus on to protective issues.

Another positive theme to emerge was the role that mobile phone contact played regarding personal safety of young people. The significance attributed to this type of contact was echoed strongly across the majority of interviews. There was an emphasis on ensuring the young person could contact the home if they were out and would be returning late. Or, if they found themselves in a risky situation, they could ring the home for assistance. Even in situations where the young person was refusing to come home, keeping the lines of communication open meant they could be contacted and their safety checked. In some cases this meant that the situation could often be prevented from being categorised as 'unauthorised absence'. Or the home could avoid using the police as a first port of call, and avert the associated possibility of criminalisation. This is an example of good practice which follows the findings of the Inspection of Child Protection Services in Northern Ireland report which voiced concern regarding the 'criminalisation' of young people's behaviour through the involvement of the PSNI which, on occasions, results in young people being remanded to the Juvenile Justice Centre (DHSSPS, 2006: 11.6.5).

Agreement existed on the need to minimise differences between young people in care and the wider population of young people (which runs contrary to the notion of greater monitoring for children deemed 'at risk'). This excerpt is representative:

"I think even for them to feel normal it's very important. Every young person out there in the world has a mobile phone. For our young people, they're even more dependent on having that if they don't have access to their family on a daily basis and they don't have access to their friends on a daily basis."

Overall, mobile phone use was viewed as part of life skills and development. Yes, it involved risks, but it was viewed as something that had to be dealt with alongside other aspects of life. Sometimes it was discussed alongside other practical issues like budgeting, for example, and ensuring phone bills were covered.

But neither did respondents underestimate in any way the significant disadvantages presented by unregulated contact via mobile phones. Disconcertingly, references to how mobile phone contact impacted on a young person's increased risk of sexual exploitation and criminality were not the exception. Specific incidents were described whereby young people had received a phone call in the middle of the night and had left the home. Other examples included young people coming back under the influence of drugs having responded to a phone call. The negative aspects of family contact meant it could be any time of the day or night. The concept of the 'needy parent' emerged here too, whereby unregulated phone calls from a parent (who was perhaps under the influence of alcohol or drugs) could prove upsetting for the young person and disrupt the whole home. One young person had received threats via their mobile phone from drug dealers who claimed they were owed money. Another had been targeted by local paramilitaries. 
Mobile phones and contact arrangements for children living in care

The greatest challenge for care home managers was reconciling these known advantages with the disadvantages. This is where the therapeutic model of working has had significant influence - because the advantages of mobile phones harmonise with the principal goals that the homes are effectively working towards.

A brief overview of the therapeutic approaches to social work in residential child care settings is given in table 3 below (see Macdonald et al., 2012 for more details). Table 4 sets out the overlap between the principal goals of the therapeutic approach and the perceived advantages of mobile phone use. 


\section{Mobile phones and contact arrangements for children living in care}

Table 3: Therapeutic models - core components

Sanctuary model

Sanctuary model

Children

Highlights the effect of trauma on children. Recognises that organisations and their staff can produce dysfunctional (defensive) ways of behaving, so change has to be at a systems level.

Incorporates a trauma-informed, shared language-SELF:

- Safety

- Emotional management

- Loss

- Future

\section{Experiences (CARE) model}

Aims to develop a competencybased curriculum to help residential care staff establish practices to improve outcomes for children.

Focuses on two core areas of competence:

1. Improving leadership and organisational support for change.

2. Enhancing consistency in and across teams in how they think about, and respond to, the needs of children in their care.
Social Pedagogy model

Based on values reflecting different approaches to children and different cultural histories of social interventions.

The relationship between child and pedagogue is important and good communication essential.

'Ordinary tasks or events' provide opportunities for development.

.

.

Attachment, Regulation and Model of Attachment Practice Competency (ARC) model (MAP)

A flexible framework that Draws on attachment theory and allows practitioners to choose research on neurodevelopment from a 'menu' of sample to help staff understand interventions organised around children's behaviour and what it three areas: attachment, self- means.

regulation and competency.

Encourages staff to think of Traumatised children are helped themselves as 'actors' rather to (re)build healthy attachments than 'observers' and to by helping carers to:

- Better understand child's behaviour and emotional responses.

- Manage their own affect.

- Provide a consistent response. recognise the effects of the emotional demands placed on them in their work with children.

The importance of authoritative parenting and attunement is also a core component. 
Mobile phones and contact arrangements for children living in care

Table 4: Perceived advantages and disadvantages from care home manager's perspective

\begin{tabular}{|c|c|c|}
\hline & Residential car & home managers \\
\hline 5 & Perceived advantages & Perceived disadvantages \\
\hline Increased family contact & Maintains family contact & Needy parents \\
\hline MAP/Sanctuary/CARE & & \\
\hline & $\begin{array}{l}\text { Provides access to wider } \\
\text { family }\end{array}$ & $\begin{array}{l}\text { Uncontrolled contact with } \\
\text { family }\end{array}$ \\
\hline & Promotes safety & $\begin{array}{l}\text { Sexual exploitation/contact by } \\
\text { inappropriate others }\end{array}$ \\
\hline & $\begin{array}{l}\text { Adds to stability of } \\
\text { placement }\end{array}$ & Bullying \\
\hline $\begin{array}{l}\text { Improved relationships } \\
\text { between staff and children } \\
\text { CARE/Social Pedagogy }\end{array}$ & $\begin{array}{l}\text { Promotes good relationships } \\
\text { between carer and young } \\
\text { person }\end{array}$ & Loss of control/powerlessness \\
\hline & $\begin{array}{l}\text { Can prevent a situation } \\
\text { becoming an 'official' } \\
\text { unauthorised absence }\end{array}$ & $\begin{array}{l}\text { Absconding (phone calls in } \\
\text { middle of night) }\end{array}$ \\
\hline & $\begin{array}{l}\text { Gives reassurance and } \\
\text { psychological comfort }\end{array}$ & \\
\hline $\begin{array}{l}\text { Competency building } \\
\text { Sanctuary/CARE/ARC/Social } \\
\text { Pedagogy/ARC/MAP }\end{array}$ & $\begin{array}{l}\text { Life learning and skill } \\
\text { development }\end{array}$ & \\
\hline Risk management & $\begin{array}{l}\text { Encouraging resilience and } \\
\text { responsibility taking }\end{array}$ & \\
\hline Sanctuary/CARE/ARC/MAP & & \\
\hline & Minimises difference & \\
\hline & Reduces discord & \\
\hline
\end{tabular}

\section{How issues are managed}

Previous research has shown how the therapeutic approaches adopted by the Trusts share many similar features in terms of core concepts and essential skills (Macdonald et al., 2012). For instance, all the models emphasise attachment, resilience and competence. Therefore, it was not surprising to find that the way issues were managed across the Trust areas reflected these similarities, albeit with some variation. This was evident in a number of common management strategies: 
Mobile phones and contact arrangements for children living in care

\section{Non-confrontational style}

Many of the homes requested that the young person hand their phone in at night, but this was not generally enforced, unless the young person agreed, which was, understandably, almost never. In the following instance, the CARE model was used as validation for adopting a nonconfrontational approach.

'Two years ago ... some Trusts undertook the Sanctuary model. We took on the CARE model which is children and residential experiences. Now, the Trust has bought into it hook, line and sinker. We still have our problems, but Ijust love it. I think it's a great way to work and it's a non-confrontational way of working. Normally, before it was all sanctions, sanctions, sanctions. Not anymore.'

A reward scheme was a common strategy whereby phone top-ups would be used as an incentive for responsible behaviour.

Only one residential home in our sample operated a policy of phone hand-in on a more forceful basis, which made the home's regime stand out as being stricter than all the others. But even here, the individual needs of the young person could dictate that this regulation be set aside. One respondent told us they would remove a young person's phone if they had concerns about inappropriate access to the internet, for example. Their phone would then be replaced with a cheaper model without internet access. However, as reported by another interviewee, this strategy was already becoming redundant as it was almost impossible to find a mobile phone that did not have internet access. Only if there were major child protection concerns might a mobile phone be confiscated. But respondents were emphatic that removal was a strategy of last resort.

There was variation in the degree to which this diplomatic style of management was practiced. The apparent lack of agreement among the HSC Trusts regarding whether or not mobile phones could or should be removed from young people as a safeguarding measure also emerged as an issue in Barnardo's report (see Beckett, 2011). This is demonstrated by comparing the following two assessments.

Respondent from Trust using ARC model:

'If we have sexual abuse or physical abuse concerns or threats or whatever, then we're very clear about the phone. We remove it, end of story.'

Respondent from Trust using Social pedagogy model:

'It has to be looked at sensibly because it is a big part of young people's culture. And even in the case of exploitation ... if you're mixing in them circles and you take a phone off a child they'll just get another phone off that person. You have to have a bit of sense around it.'

How much this variation in the management of mobile phones can be attributed to the particular therapeutic approach adopted in the Trust, or to the individual home manager's interpretation of the model, is debatable. The first comment was made by the same care home manager who ran a stricter regime about phone hand-ins than most others. 
Mobile phones and contact arrangements for children living in care

\section{Relationship building between the young person and staff}

Relationship building within the residential setting was specified by all as a means of managing issues. The therapeutic models adopted comprised the biggest driver in this respect. Managers discussed how creating good relationships with young people in their care was their main focus of working. Interviewees commented on how they believed their own specific model was successful in facilitating open communication and promoting trust between the young person and the residential staff. Explanations of these strategies often made references to the specific care model. However, as shown in the two excerpts below, the work in this area is not unique to one or other specific model. For example, the following manager highlighted the success of the MAP approach in relationship building:

'The Trust is now pursuing the model of attachment promotion - MAP it's called. We've found with this whole approach, with the promotion of relationships, especially between key worker and young person...the relationship is as much important to the young person as it is to the member of staff. Quite often they will share all issues you know.'

So too did the following manager who explained how they were working intensively under the ARC model:

'Our emphasis here is about building relationships with our young people so they feel open enough that they can talk to us about anything... We focus heavily on attachment and relationships.'

From our understanding, the goal of relationship building was embedded within all the therapeutic approaches being employed. The influence of this objective was visible in several spheres, even down to how practical decisions were made on the specifics of the internal contracts between young people and the home. For example, the following home manager explained how their internal contract was a verbal agreement, negotiated and agreed according to the ethos of the particular home's model:

'The whole ethos of this home is all about attachment and relationships. There's a very specific approach being used and approved by the Trust [MAP]. So there's verbal contracts. We very much promote the relationship. I mean, we don't expect any child to be an angel. Now, it's all communicating with them and re-establishing links and rebuilding bridges.'

\section{Relationship building between the young person and their family}

As discussed earlier, managers felt the benefits of mobile phone use for contact with the family, outweighed any disadvantages to the young person. The degree to which promoting family contact was rationalised as a managerial strategy was linked to whether or not it was a core goal of the home's therapeutic model. In the example below, the interviewee was explaining how they had no written contract or agreement on the use of mobile phones. While the issue may be discussed in meetings with the young people in care, the approach was all about promoting relationships and 'generating more contact'. The CARE model was the approach in question, which, as the manager explains in the following excerpt, took time to be established:

'I keep going back to the CARE model here because it really is massive with ourselves at the minute. This is the model we're working under ... it's not 
Mobile phones and contact arrangements for children living in care

about punishing these children when they're in care; it's about safeguarding them when they leave. One of the things in the CARE model that came across to me was family contact regardless. It was something that really messed with my head. I really had problems with that concept because I looked at the young person and the majority of the problems came from home. So why should we be promoting that? But what they're saying is - when this guy turns 18 years of age he will be going home. So it's about us helping them people to work better together. It's about helping them develop better skills, better coping tactics in times of crisis, so it makes sense.'

\section{Inclusive home meetings}

Regular house meetings were a common platform for bringing current issues to the fore for discussion. Some homes organised meetings on a monthly basis, others twice a month, some held them every week. Generally, the agenda was left open as far as possible, and the meetings were usually run on an informal basis. Some respondents saw the house meetings as an opportunity to work through the issue of mobile phone use informally, without having to initiate it through a LAC review.

Sometimes outside agencies were used to facilitate a type of peer education, although this was not universal as some home managers reported a preference for an 'in-house' programme of educating. Other young person's advocacy organisations were used to discuss numerous issues, which sometimes included mobile phone use. Some managers asked previous residents to come back and talk to the current group of young people. These were things that respondents felt could be used more widely.

\section{Encourage responsibility (resilience)}

Some managers linked the management of risk, as opposed to avoiding it, with encouraging resilience and preparing young people for life's challenges. These respondents saw risk taking as part of everyday life, and viewed it as a way of encouraging young people to take responsibility. However, some tension was reported between the respondent's style of management and the views of individual social workers who, it was believed, were more risk averse. However, despite the many challenges of mobile phone use, the view here was that life was full of risks and learning to manage these risks was a journey towards independent living.

'We have one young person here...she would have contact with her mother unfettered by us through phone contact. However, for face-to-face contact we would agree to drop off and make sure mammy is sober...so it's immediately contradictory. But again, we're relying on the resilience of the girl and we're monitoring it.' (MAP respondent)

\section{Restricted internet access}

One theme emerged which contradicted all other styles of management. This was the level of restriction on internet access via the home's personal computers (PCs). All homes had PCs installed but the common practice across all homes was to have strictly limited access to the internet (again, with some variations in the degree of stringency). This seemed to be in opposition to the more relaxed attitude to mobile phone use. For example, it was common for 
social networking sites like Facebook to be blocked completely. Access that did exist was heavily supervised. In at least one residential home, there was no internet connection at all. To a large extent this made mobile phones even more essential. It was an internal debate that some managers admitted they had among themselves, as is evidenced from the following interview excerpt:

'In terms of advocating for the young people and the obvious benefits...balancing that with the safeguarding and everything that goes with it, is a fine line to tread at the best of times. Quite often we would find here that we would come up against a lot of rigid attitudes...generally on the more risk-averse side, where people would be more inclined to say "no, no, absolutely no; they can't have access to this and this and this. And sometimes arguing the case for managing risk as opposed to trying to avoid it, is the frustrating part of it for us.'

It is highly likely that because the PCs were Trust owned property (as opposed to mobile phones which were personal property), it made them easier to regulate. It also meant regulation of procedures could be vulnerable to reactionary responses to isolated incidents. One clear example of this was given by a respondent who discussed an incident where the parent of a young person in another Trust area was threatening legal action because their child had accessed Facebook while in care. The respondent said he received a letter that same day from the Assistant Director of his own Trust directing that 'everybody make sure nobody's using Facebook'. The respondent admitted that this advice might work on a computer on the Trust premises, but not in a home setting. So in reality it was not very rational guidance.

Recommendations built on reactive responses are not always helpful or realistic. For one respondent, they chose to ignore advice from the Trust to remove mobile phones from the children, in reaction to a specific incident. The respondent believed it was an over-reaction on behalf of the Trust and took what they believed was a more realistic response:

'One time we actually got an email because there was an issue with...it was kind of messing about and children took a little video and there was an issue about that, you know, having videos... But we chose to not agree with that and to still allow our young people to have their phones because it's a big part of their culture. So we thought we'd keep it quiet and we just let them do it anyway. That was probably the best way of going ahead with it.'

It was not clear how or if the Trusts monitored these directions given regarding access to Facebook and the use of mobile phones.

\section{Staff training}

Most home managers reported the attendance of staff at periodic training events on the wider issue of internet safety. It is not clear whether or not such training alluded to mobile phone use in general, but would not have incorporated the issue of contact. In any event, the effectiveness of such training was not clear, given that the self-confessed deficit of technological knowledge was a recurrent theme among the interviewees. Some managers felt that generic internet safety training being offered could be a bit 'over the top'. One manager explained it this way: 
Mobile phones and contact arrangements for children living in care

'I sent four members of staff on a day training safety event jointly run by the PSNI and voluntary agencies. They came back nearly ripping the PCs out of the wall - they can get a bit OTT with it.'

\section{Overview}

There was a strong sense among care home managers of inevitability. Mobile phones were viewed as part of everyday life for all young people, not just those in care. As such, it was impossible to police their use. In fact, the over-riding feeling was one of powerlessness. The general feeling was that there was little point in drawing up plans if they were not going to be realistic or achievable. In the main, negotiation and relationships, encouraging young people to take responsibility and realising that actions have consequences was felt to be the best course of action.

Removal of mobile phones was a course of last resort. But in cases where there were serious concerns, it was the only alternative.

Most of the issues raised during the interviews were common to all trusts although some were more salient in individual trusts. This could often be accounted for by the group dynamics within the home at the time, the individual characteristics of the young people in residence and geographical location. The therapeutic approach adopted by the home was seen as the main driving force in determining how issues regarding mobile phone use were managed. There was an on-going struggle for managers to reconcile the advantages of mobile phones against the disadvantages. This was made more complex because of the overlapping relationship between the stated core goals of the particular model and the positive outcomes of mobile phones. However, the general consensus was that the advantages outweigh the disadvantages.

However, this raises the following question: Has the desire to achieve the model's core goals shaped people's perception of positive outcomes or have the positive outcomes been achieved as a direct result of the implementation of the model?

While the focus of this study was on mobile phones and contact arrangements for children living in care, one care home manager expressed concern about the use of social networking sites by some young social work staff. Their view was that by posting up photographs of themselves on Facebook while out partying, the adults in question were putting at risk their 
Mobile phones and contact arrangements for children living in care

professional standing of role model for young people in care. It would be useful to know whether the Trusts have specific policy on the use of networking sites such as Facebook by staff and any potential implications this may have for the Code of Practice for Social Care Workers which stipulates that social workers must not:

Behave in a way, in work or outside work, which would call into question your suitability to work in social care services. (NISCC: 5.8). 
Mobile phones and contact arrangements for children living in care 


\section{CHAPTER FIVE - EXPERIENTIAL LEVEL}

\section{Introduction}

This element of the research was designed to explore how mobile phones are used by young people. Postal questionnaire-based surveys were carried out with foster carers to examine the nature of mobile phone communication, with particular emphasis on the young person's contact with family and friends. A number of open-ended questions were included which allowed foster carers to expand on their response in places. These have been used in the analysis to illustrate the diversity of opinion. The intention at this level of the study was to understand, from the perspective of the foster carer, the extent to which mobile phone contact enhances contact; causes or exacerbates problems in the placement and/or for the young person, and what problems, if any, foster carers have in monitoring and supervising this form of contact.

This information was augmented by the data from the questionnaires completed by young people living in foster care and residential care homes. These focused on the everyday routines of mobile phone use; the perceived benefits, particularly in relation to contacting their family and friends; what, if any, problems they experienced and, from the young person's perspective, how mobile phone contact helps or hinders their life away from their family of origin.

\section{Foster Carers}

\section{Respondents}

Completed questionnaires were returned by 128 foster carers, the majority of whom were female (87\%). Respondents were mostly aged between 41 and 59 years (see table 5), with some younger $(14 \%)$ or older $(13 \%)$.

Sixty-eight percent described their child's current placement as long-term foster care (see table 6). Kinship care was the next most common. Emergency, respite and intensive support care was the exception.

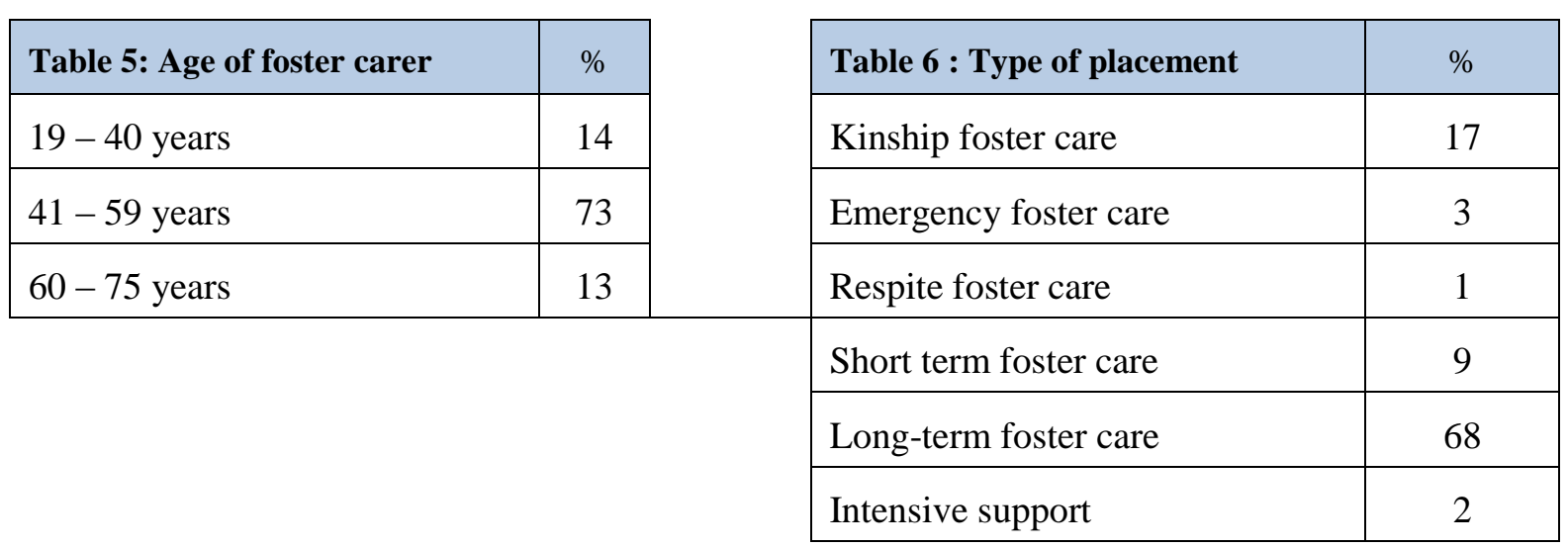




\section{The children they cared for}

The placement profile was reflected in the number of years the child lived with the carer. The majority of young people had spent three years and more (61\%), and another $21 \%$ had been in their placement for between one and two years. Short-term placements of less than a year were the minority, with $18 \%$ of foster carers reporting this type of placement. This reflects the status of children in care in Northern Ireland (DHSSPS, 2013) where a quarter (25\%) of children have been in care for less than one year.

Most children being cared for were aged between 11 and 16 years (see figure 1 below).

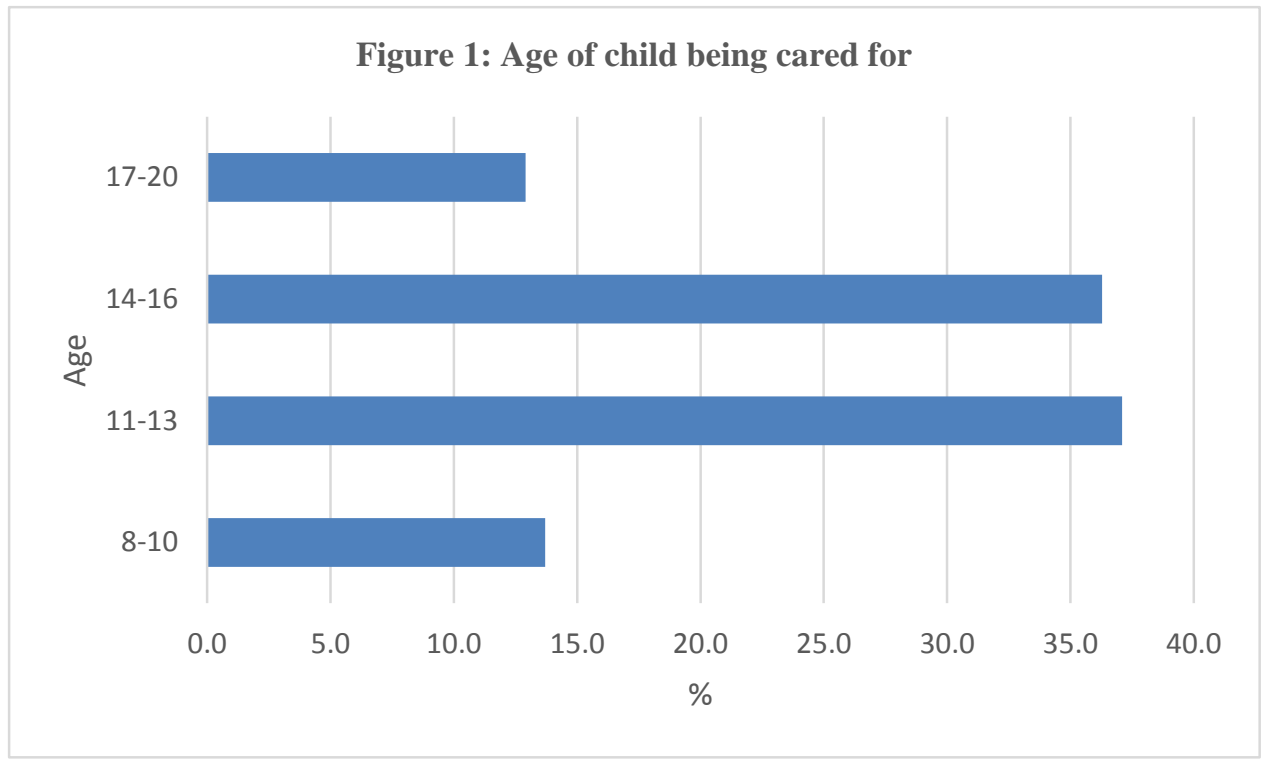

The vast majority of young people being fostered were in care under a care order $(72 \%)$. Twenty per cent were in voluntary care, and the remaining $8 \%$ were there on an interim care order. In terms of number of placements experienced, $41 \%$ had had between two and three previous placements. Almost a quarter of young people (24\%) were covered by a statement of special educational needs.

The long-term status of most placements meant that the foster carers were in a good position to give a reasoned view on how mobile phones were being used in relation to maintaining contact with family and friends.

\section{Mobile phone use for contact}

Foster carers were asked a number of questions about whether and how their foster child used their mobile phone to keep in contact with birth relatives. They were encouraged to describe the nature of the contact.

Just over half (54\%) said their foster child did use their mobile phone to contact their birth relatives. Contact with birth relatives was reported between the young person and their birth parents, siblings, aunts, uncles, grandparents and sometimes cousins. Most frequently, contact was described as general chat such as keeping up to date with family news - this happened on a regular basis. The majority of contact was described positively as proactively maintaining relationships with the wider family network. However, there were reports where contact was not a positive interaction, and where examples of negative consequences reflected those 
described by the residential care managers. Foster carers described incidents where birth parent/s placed high demands on the young person to contact them constantly. The birth parent/s need for constant reassurance could result in the young person receiving phone calls during the night. Alternatively, young people could feel rejected by unreturned or sporadic contact from their birth relatives. For a few foster carers, such unconstrained contact was directly linked to problems such as the young person contacting their birth parent to complain about their placement or to ask for something which their foster carer had refused. Of foster carers whose child did use their phone for contact, around one fifth provided examples of problematic contact.

Foster carers were asked whether mobile phone use had been discussed at the child's LAC review. The sample was split evenly, with half reporting that this issue had been discussed during the LAC review and the other half reporting that it had not been part of the discussion. Where the topic had been discussed, this appears in most cases to have been triggered in response to an issue having been previously identified; for example, as a result of prohibited contact with birth relatives, or mobile phones having been inappropriately used in the past for instance taking unsuitable images or distributing people's phone numbers to others unknown to them. Discussions focused on reaching compromises and agreement on the use of mobile phones for contact purposes. This might include placing limits on the young person's mobile phones use, such as limited access outside contact days or, on occasion, removal of the phone completely for a certain length of time. In some cases, discussions about mobile phones during a LAC review were initiated by the foster carer. This mostly involved the setting of boundaries which sometimes ran contrary to the wishes of the birth parent/s. For example, where the foster carer perceived that mobile phone contact with birth parents was intruding on the privacy of the foster family. Another example was given by one respondent who explained that their foster child's birth parents requested the child have a mobile phone whereas the foster carers believed the child was too young. In a small number of cases, a court decision was in place regarding family contact via phone, although generally these mandates were not proving successful as a method of stemming prohibited contact.

Considerably fewer foster carers reported the young person's mobile phone use as forming any part of his or her care plan - only 13\%. Again, in the majority of cases, this was usually the result of an on-going concern or assessment whereby rules and boundaries were being set and monitored.

Typically, contact arrangements between the young person and their birth parents/family were highly specified. Respondents described contact arrangements stipulating the exact number of hours/days per week/fortnight/month/year according to the individual family member involved. A young person's contact arrangements could be two hours, four times a year with one parent and, with the other, two hours on one specified day of the week and three hours on another specified day of the same week. The pattern ranged from no contact to supervised contact to daily unsupervised contact (although daily contact was not common). With the exception of a very small number of cases where the young person was free to arrange their own schedules, contact arrangements were rigidly adhered to. The main point here is that, despite the formality of arrangements, over half of our respondents reported their foster child using mobile phones to keep in contact with their birth relatives. 
When asked whether mobile phone contact would contravene any conditions within the care plan, $35 \%$ of foster carers agreed that it would. One of the main reasons why mobile phone use constituted an infringement of the care plan was the supervised nature of existing contact arrangements. In these cases, foster carers acknowledged the contradiction between supervised contact and unregulated contact through mobile phones. The main concern for these foster carers was the perceived potential this type of contact had to cause additional upset or anxiety to the child, or have negative effects on their behaviour. This was exacerbated by the difficulties of monitoring mobile phone contact. Examples were given where the foster carer believed mobile phone contact had been used by the birth parent/s to deliberately undermine the placement. Examples included birth parents phoning the young person telling them to ask the social worker for more visits; of telling a young person to complain to their social worker about the foster carer; and the example already referred to of 'needy parents' wanting reassurance or wanting to tell the child their problems. A small number of carers within this sample gave examples of the young person's parent arranging to meet up with them without the knowledge of the foster carer. These meetings were perceived as precarious in regard to the child's wellbeing.

\section{How foster carers manage mobile phone use}

Foster carers were asked whether they had given their foster child advice in particular areas regarding the use of their mobile phone. Almost all carers reported giving advice in all areas we enquired about, particularly in how to stay safe on-line and how to use their mobile phone responsibly (see table 7 below). Ninety-five per cent of foster carers talked to their foster child about staying safe on-line, and $89 \%$ talked about managing contact with birth family and relatives.

Table 7: Topics discussed with children and young people

\begin{tabular}{|lll|}
\hline Topic discussed & Yes & No \\
\hline How to use their mobile phone responsibly & $92 \%$ & $8 \%$ \\
\hline How to stay safe when on-line & $95 \%$ & $5 \%$ \\
\hline Dealing with nuisance calls & $88 \%$ & $12 \%$ \\
\hline Cyber, text bullying & $88 \%$ & $12 \%$ \\
\hline Managing contact with birth family and relatives & $89 \%$ & $11 \%$ \\
\hline Relationships & $89 \%$ & $11 \%$ \\
\hline
\end{tabular}

The majority of foster carers had a firm set of rules regarding mobile phone use (79\%). These mostly involved switching the phone off at bedtime (usually between 9pm and $11 \mathrm{pm}$ ) and/or leaving the phone down stairs when going to bed. Oft cited rules included: not taking mobile phones into school; not making contact with people they are not allowed to have contact or unsupervised contact with, and agreeing to have their phone checked intermittently. Not using their phone at the dinner table was another common instruction. We were interested in knowing how these rules were developed, for example, if the young person had been involved in setting these rules and the degree to which the rules were abided. 
In $58 \%$ of cases, the young person had, to some degree, been involved in setting the rules. Mostly, this involved taking part in a discussion where the reasons for the rule setting were explained. Unsurprisingly, being involved in this way did not always correspond with agreement of decisions. In some cases, foster carers described how the rules had been accepted but then broken afterwards. However, most carers believed that, even though there was initial resistance, the rules were accepted with some degree of reluctance. What is interesting is that only 6 foster carers (approximately 10\%) received input or guidance from the child's social worker in the setting of rules on mobile phone use.

More than two-thirds of foster carers $(65 \%)$ believed a mobile phone was 'essential', 'very important' or 'important' for their foster child's social life. Far fewer (31\%) believed a mobile phone had a positive effect on the stability of the young person's placement. In $24 \%$ of cases, mobile phones were believed to have a negative effect on the placement (see above). However, most people thought it had no effect at all or were undecided (45\%). Foster carers had an opportunity to elaborate further. Those who had strong views (either positive or negative) were more inclined to broaden their response. The reasons given for these feelings were a reflection of the known advantages and disadvantages discussed above. Specific examples of each are:

'It helps ensure her safety when out and about, gives her the freedom to participate in more social activities and she is able to stay in contact with friends and make arrangements with them. Helps us be aware of where she is and that she can contact us if and when needed.'

'Children have used the phone to contact parents who will tell the child 'you don't have to go to bed if you don't want to' or 'tell them it's none of their business'. It can be very hard if a parent is using the mobile to control the child.'

Foster carers face the same conflict as the residential care managers and key personnel discussed earlier - the benefits are significant but the negatives are substantial. This is exemplified in the response given by one carer who could not decide between positive or negative effects:

'I feel if monitored and used correctly, it helps them to have contact with parents. However, there were times when it was not helpful, for example, at the beginning of the placement when the child was settling in and getting used to new boundaries. If they didn't like something they could give one piece of information to parents on the phone, completely out of context and mislead the parent. Also, constant contact at the beginning meant parents used the child as 'piggy in the middle' to relay messages to each other. A positive is we know when phone rings, who it's for and who is ringing. I like to know where he is at all times. He lets me know when he is coming home or any change in our arrangements and I would agree a time.'

However, overall, the general perception was positive, strengthened by the pragmatic view that mobile phones are a way of life for all children, not just children in care. Negotiation and explanation were both thought to be central to making it less problematic.

When foster carers were asked whether there was an expectation that calls and texts to the child's mobile phone were private $-57 \%$ agreed that there was. However, when we asked 
foster carers if they had ever checked phone messages or call logs, $71 \%$ said they had. This reflects the fact that having their phone checked intermittently was a common 'house rule' cited by foster carers. The vast majority of people who did not believe that calls and texts were private, had checked the child's phone messages and/or calls (87\%).

\section{Guidance from social worker}

To help complete the picture, all foster carers were asked if they had ever been requested, as part of a care plan, to monitor or regulate their child's phone use. Almost two-thirds said they had not been asked to do this (64\%). All but $12 \%$ of the third who said they had been asked to do so, complied with the request. Foster carers who did not comply were also more likely to view calls and texts on their child's phone as private.

In general, requests to scrutinise mobile phone use were made if there was a history of negative communication to/from the child and their birth family - communication that it was thought could harm the young person or the stability of the placement. Advice included checking texts to gauge the appropriateness of the language, ensuring phone calls were made in a public part of the house (the kitchen was specifically mentioned) and watching for body language that might indicate distressing interaction. It is difficult to assess the usefulness of this advice as some foster carers spoke about their child using coded texts or keeping their contact numbers under pseudonyms. In addition, $13 \%$ of carers reported that the young people in their care had more than one phone and $12 \%$ said their foster child had more than one sim card.

For one foster carer, whose current experience was very negative, the advice had been to encourage the child to use the phone in the kitchen when contacting his or her parent, so their body language could be observed for signs of stress. While the foster carer acknowledged that this advice had so far helped in relation to child-parent contact, she noted the ineffectuality of such advice in relation to parent-child contact. The foster carer posed the following question to the researchers:

'What is the point in removing a child from an abusive parent and allowing parent to continue to abuse child in foster carers home via mobile phone? Is it fair on foster carers - having to deal with the fallout of mother's phone calls?'

For another foster carer, the advice from social workers was perceived as unnecessary and intrusive. The respondent complied for a while, but believed that as long as the young person abided by the rules, it was better to work on a trusting relationship.

'At the beginning I was asked to monitor his messages. I did a few times, but felt it wasn't right as it was just childish stuff and sometimes embarrassing for him.'

\section{Children and young people living in foster care}

The aim of this section of the study was to focus on how, where and when mobile phones were used by children and young people living in foster care. We were interested in drawing out problems that been encountered, for example from unwanted calls, but also the perceived benefits, particularly in relation to contacting their family and friends. Generally, we wanted 
Mobile phones and contact arrangements for children living in care

to discover whether and how they felt mobile phones helped or hindered their life away from their family of origin.

We received 83 completed postal questionnaires from 42 males and 41 females. The majority of respondents were aged 16 to 18 years, with only $10 \%$ aged between 10 and 12 .

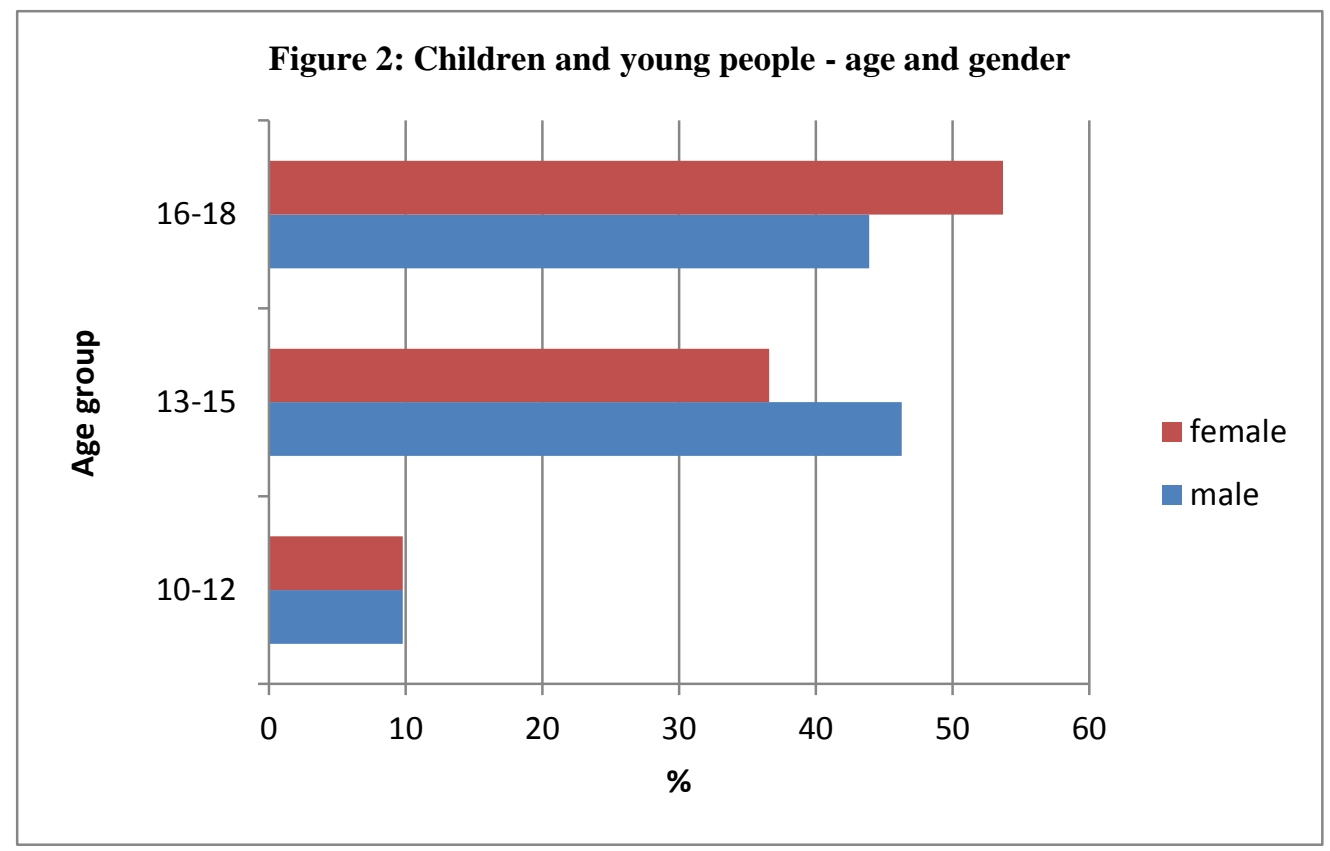

To build a picture of the current situation, some general questions were asked about the type and status of the current placement. The length of placement was a reflection of the foster carers' registration, with the majority of placements being long-term:

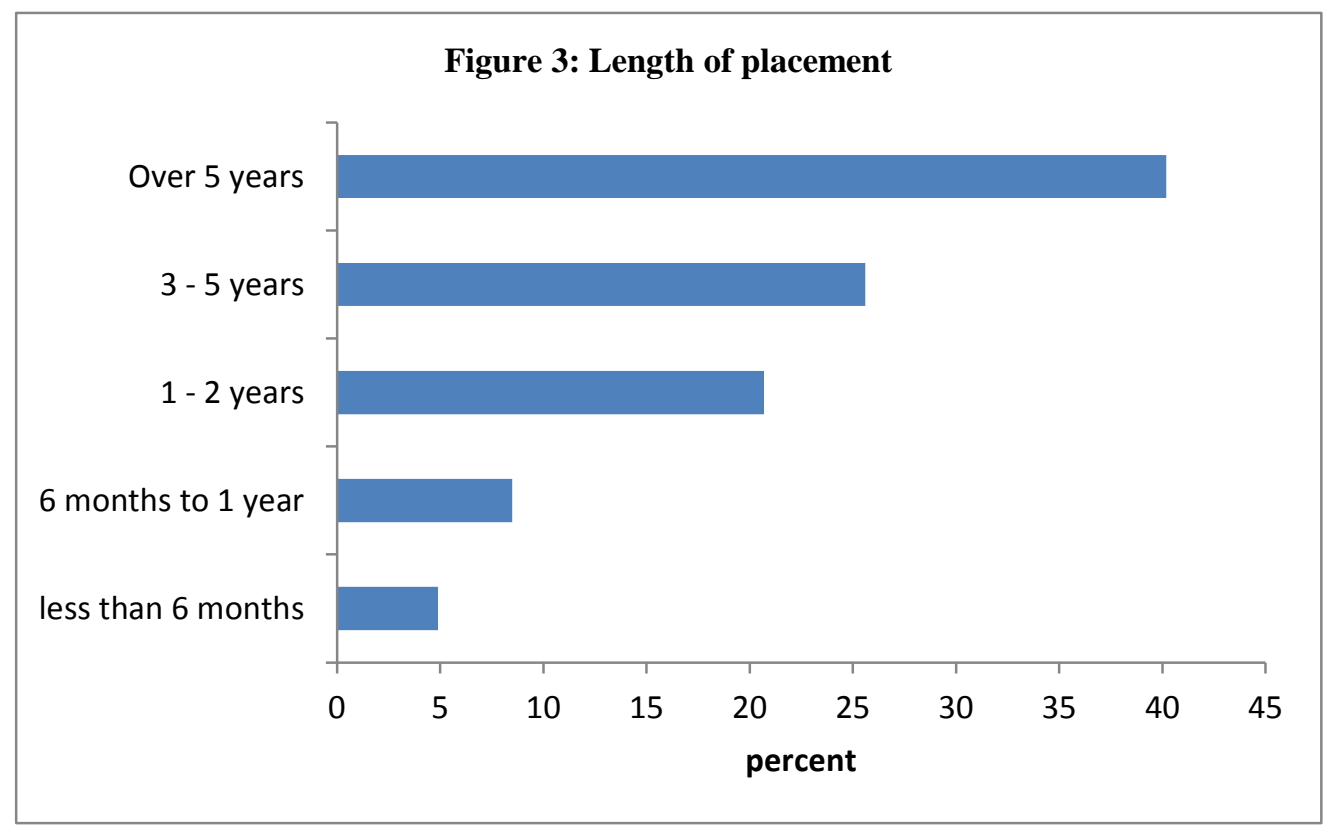

In regard to the number of placements, most young people reported having two to three placements. For just over $30 \%$, this was their first placement. 
Mobile phones and contact arrangements for children living in care

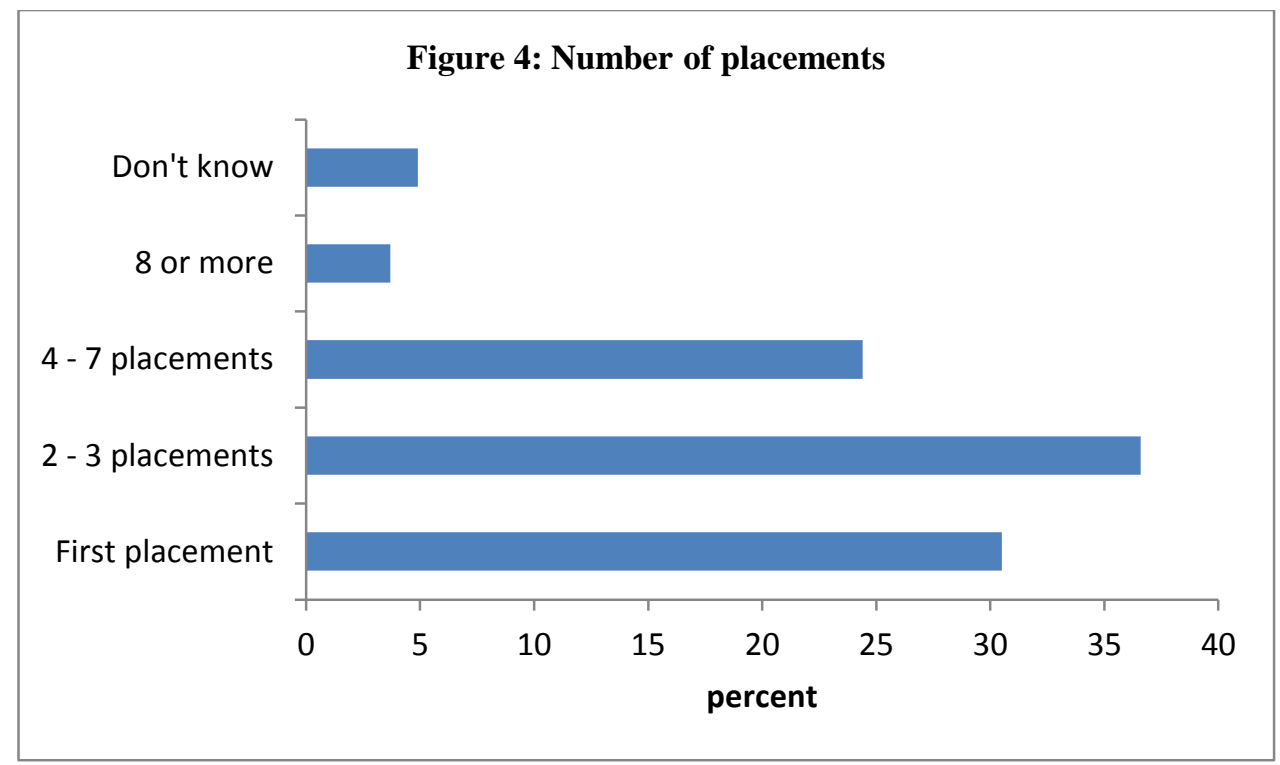

Amongst those with more than one placement, the number of young people who said they ended the last placement (12\%) was similar to the number who said their foster carer had ended the placement (14\%). Quite a few did not know who ended it (17\%). Only a small number of respondents said contact with birth family was a reason why their previous placement ended $(10 \%)$. With the caveat that these are small numbers, it is still worth noting that, in no instance where contact with birth family was a reason for the placement ending, did the foster carer instigate the termination.

\section{Mobile phone usage}

All but six respondents said they owned or regularly used a mobile phone. Of the six who did not, two were in the youngest age group (10-12) and four were in the 13-15 age group. Half of all young people said they used their mobile to contact their foster carer on a daily basis and vice versa. Other than that, telephone contact between the young person and their carer was at least once or twice a week.

The majority reported that they were permitted mobile phone contact with birth parents (67\%). Again, the most common pattern of young person-birth parent contact was either on a daily basis or once or twice a week. However, of those who were allowed contact via mobile phone, $20 \%$ hardly ever contacted their parents in this way and 34\% said their birth parent did not use this form of contact. Very rarely was phone contact with birth parents reported in cases where it was not permitted, though in one case where such contact was not permitted, the young person and their parent were in phone contact every day. In contrast to contact by mobile phone, $84 \%$ said a house phone (land line) was hardly ever used any more as a way of communicating with birth parents.

Regarding face to face meetings with birth parent/s, the most common arrangement was to meet a couple of times a month $(37 \%)$. The more regular the physical contact, the more frequent the mobile phone was used for contact. Amongst those who said they hardly ever or never met up with their birth parents, half had used their mobile phone for contact - this ranged from every day to at least a couple of times a month. 
The most common age when young people reported getting their first mobile phone was between the ages of 9 and 14, although 15\% said they got their first phone when they were younger than 8 years old. Young people were more likely to receive their first phone from their birth parents $(42 \%)$, followed closely by their foster parents $(39 \%)$. Five per cent said they bought the phone themselves, and a few reported receiving their first phone from other family members including siblings, aunt, uncle and grandparent. The majority said they had one phone and one sim card, but $17 \%$ reported having two phones and a similar number said they had two sim cards. Having more than two phones was not common. The foster carer was the person most likely to pay running costs for the phone, followed by the young person themselves. This was still the case when the young person said they had two phones.

To aid comparison with the foster carer responses, young people were asked whether their foster family had talked to them or given them advice in the same areas detailed in table 7 above. The high numbers of young people reporting having received advice from their foster carer on these issues confirms the picture presented by the foster carers. The rules were also consistent with what carers reported. However, a smaller percentage said their foster carers had rules about their mobile phone use (55\%) than was reported by carers themselves $(79 \%)$. Equally, a smaller percentage of young people said they helped their foster carers develop the rules $(26 \%)$.

Compared with foster carers, a higher percentage of young people (77\% and 65\% respectively) reported that their mobile phone was essential or important for their social life. The main cause of argument between young people and their foster carers revolved around not being allowed to use their phone after a certain time at night. Most young people were adamant that foster carers should not be allowed to read their texts (65\%). Some were unsure about this and $16 \%$ thought they should be allowed to read texts. Just over half of young people who completed the questionnaire said their foster parent had checked their phone messages (52\%).

\section{Young people in residential care}

Only a small number of young people in residential care completed the questionnaire - 18 males and 7 females. Their ages ranged from 13 to 18, with the majority aged between 16 and 17 years. Similar also was the long-term nature of the placement, with $64 \%$ being in residential care for two years or more. Only three respondents did not own a mobile phone. In the majority of cases, contact with birth family was not cited as a reason why a previous placement ended, although six young people were unsure if it was or not.

Very little difference in mobile phone use was apparent between care settings. Mobile phone contact between the young person and their social worker/field worker or carer was regular more than half reported contact via phone either every day or once or twice a week. The numbers reporting contact from their social worker/carer to them was higher $(60 \%)$ than reported contact between young people in foster care and their carers. Only two young people were not allowed mobile phone contact with their birth parents. 
The only apparent differences were the lower numbers reporting that staff had given them advice in the areas described in table 7; that there were rules about mobile phone use; or that they had been involved in setting these rules. As with young people in foster care, most were adamant that their texts should not be read. The only difference was, a higher number said their phone had not been checked by their carer. However, because of the low response rate, these differences cannot be viewed as reliable, although in all other respects, circumstances were very similar.

\section{Supplementary research}

The Mind Your Health study interviewed 250 carers of looked-after children and young people ${ }^{3}$. A total of 53 respondents provided data relevant to this study (the child owned a mobile phone and the respondent was willing to answer the questions).

Analysis of the data resonate with the findings of the main study. That is, the majority of young people used their mobile phone to contact a range of birth family members, including parent/s, siblings, and grandparents. Contact via mobile phone ranged from daily contact to no contact. Mostly, contact was viewed as proactively maintaining family relationships. However, here too, a small number of carers reported this type of contact as problematic. For example, in one case where contact was prohibited under a Care Order, the child's birth mother was making contact via mobile phone. The foster carer reported this contact as one way - with the mother always initiating contact. Another foster carer reported steady contact from the birth parent to the child, promising the child they would be coming back to live together soon, thus undermining the child's chances of settling into their placement. In another instance, the birth parent was permitted limited contact which the foster carer suspected as being more regular than allowed.

The majority of carers monitored the child's mobile phone use to some degree. As above, this usually entailed house rules such as no phone after a certain time on school nights. Regulated or monitored contact via mobile phone was requested by Social Services in ten of the 53 responses. Here too, the situations are similar. In one of these examples, the foster carer was informed by their social worker that the child was not allowed a mobile phone that had internet access due to making inappropriate contact with adults via skype. However, the child's birth mother used her parental rights to overrule this decision. In a second of these examples, the foster carer believed the child should not have a mobile phone, but could not overturn this decision. Another carer felt the advice to monitor the phone was pointless as the child was much more adept in the use of mobile phones than they were. Conflicting opinion on advice received was reported by one foster carer who was instructed by a court order to remove the young person's phone for three months as a condition of bail. However, this was viewed as counterproductive in relation to the young person's safety. It was explained thus:

\footnotetext{
${ }^{3}$ This includes foster carers, residential carers and carers of children at home with a care order.
} 
Mobile phones and contact arrangements for children living in care

In terms of his safety when he was out, it was actually a hindrance because we couldn't keep in touch with him and know where he was. His mum would be the same. She would keep in touch with him and let us know where he is. She couldn't do that either.

The main point to draw from these responses is that the principal issues highlighted in the Mobile Phones and Contact Arrangements for Children Living in Care study remain topical.

\section{Overview}

The majority of foster carers and children in foster care who completed the questionnaires were involved in long term placements. Half of foster carers had discussed the issue of mobile phone use for contact purposes during a LAC review. In most cases, this was due to the issue being previously identified as an area of concern. A much smaller proportion of foster carers (13\%) reported mobile phone contact forming part of a care plan. Again, this was often because of an on-going concern.

Despite contact arrangements being highly specified in relation to meetings or correspondence, $35 \%$ of carers said their foster child's current mobile phone contact with birth relatives would contravene this plan. It was difficult to gauge the applicability of advice foster carers received from social workers for two reasons. First, guidance was generally given only when a problem had already been identified; secondly, the advice given typically proved relatively easy for either the child or birth parent to circumvent (no care plans were accessed in this research). Foster carers faced similar problems regarding conflict between the known advantages and disadvantages. However, overall the majority perception of foster carers was a positive one, based on pragmatism and realism - mobile phones are a way of life and negotiation and explanation are central to managing the issue.

The majority of young people in foster care were permitted mobile phone contact with birth relatives. Contact via landline phone was almost obsolete. However, not all who were allowed mobile phone contact with birth parents availed of it and vice versa. The more regularly young people met up with birth parents, the more often mobile phone contact was reported. More young people, compared to carers, identified their mobile phone as essential for their social life.

Very few young people in residential care took part in the survey (a response rate of 9\%). Completed responses showed a similar picture. Apparent differences cannot be viewed as reliable due to sample size. 
Mobile phones and contact arrangements for children living in care 


\section{CHAPTER SIX - WHERE WE ARE NOW}

On the basis of the evidence from this study, we have concluded that, at the time the research was carried out, no policy guidance existed on the use of mobile phone for contact, either at regional level, Board level or at Trust level. We have since made contact with key personnel at regional, Board and Trust level and to date, this remains the case (three years on): there is no policy guidance on the use of mobile phone for contact purposes.

The HSC document Practice Guidance on Assessing and Planning Contact for Looked-after Children (HSC, 2012a) exists to assist staff in particular cases where contact arrangements are potentially difficult. It is not intended to be used in all cases, rather it is for use when Trusts have identified cases which require contact arrangements to be examined in-depth. The guidance does not specifically focus on mobile phone contact per se but it does facilitate the collection of valuable information to aid the assessment of contact in difficult cases.

Regarding mobile phone use generally, children and young people going missing after receipt of texts or phone calls has been identified as an indicator of child sexual exploitation in a departmental regional policy (HSC, 2012b). What exists is described here as 'house rules' in the form of a contract to be agreed between the young person and their carer as to their commitment to abide by the rules.

The current situation is set out in table 8 (overleaf). This situation gives rise to a number of main areas of concern.

Firstly, the lack of guidance on mobile phone for contact purposes at regional level has resulted in an inconsistent approach at Board and Trust level. This has implications for realising separate policy objectives which are predicated on the assumption that such guidance is readily available. For example, in accordance with DHSSPS guidelines on delegated authority to foster carers in Northern Ireland (DHSSPS, 2010), foster carers should generally hold delegated authority for mobile phones. The detail of this authority is set out thus:

\section{Mobile telephones:}

Foster carers should be responsible for making decisions regarding the possession and use of mobile phones as they do for their own children. They should receive clear guidance and agreement re the young people's use of mobile phones and any particular restrictions should be specified at the time of placement or if concerns arise at a later stage.

It states clearly that foster carers should receive 'clear guidance' on the young people's use of mobile phones. Therefore, this recommendation is compromised by the lack of such guidance at regional level. This is important because unclear guidance regarding the use of delegated authority was one of a number of key concerns raised in the recent RQIA review of statutory fostering services (RQIA, 2013). This review highlighted how foster carers reported inconsistency in the application of that authority between the Trusts. We believe the lack of guidance intensifies the inconsistency of delegated authority procedures.

Secondly, foster carers need to be made aware of the implications of mobile phone contact (both positive and negative) in order to make informed assessments and plan accordingly. This requirement was emphasised by key stakeholders and should be incorporated into any training procedures for prospective carers. In addition, the range of information made public on social media networking sites should form part of any awareness raising preparation strategy. 
Thirdly, the status of a text message or mobile phone call as a form of 'official' contact between social worker and child or young person is imprecise. In light of Recommendation 60 of the DHSSPS Social Services Inspectorate Report (DHSSPS, 2006: 11.26), the extent to which this form of communication is officially documented as fulfilling statutory responsibility, is unclear.

Fourthly, the dynamics of mobile phone contact, which emerged during interviews with residential care managers and through the foster carer survey, draws attention to the sensitivities surrounding the nature of communication between parent-child. In most cases this type of interaction was reported as helping to maintain relationships with family and friends. However, 'needy parents' unable to place their child's needs ahead of their own, posed potential risks to placement stability in approximately $20 \%$ of instances recorded by foster carers. Clearly specified parent-child mobile phone contact arrangements, incorporated within formal agreements, would help mitigate any misunderstandings in this area.

Table 8: Policy guidance on the use of mobile phones for contact and other use

\begin{tabular}{|c|c|c|}
\hline Organisation & $\begin{array}{l}\text { Evidence of specific } \\
\text { policy in relation to } \\
\text { mobile phone for contact } \\
\text { purposes }\end{array}$ & $\begin{array}{l}\text { Evidence of other policy/guidance on mobile } \\
\text { phone use }\end{array}$ \\
\hline DHSSPS & None & \\
\hline \multirow[t]{2}{*}{$\begin{array}{l}\text { Health and Social Care } \\
\text { Board }\end{array}$} & None & $\begin{array}{l}\text { Practice Guidance on Assessing and Planning } \\
\text { Contact for Looked-after Children (HSC, 2012a) } \\
\text { focuses on overall contact issues in-depth and is } \\
\text { intended for use when contact is deemed } \\
\text { potentially difficult. }\end{array}$ \\
\hline & & $\begin{array}{l}\text { Regional Residential Childcare Policies (February } \\
2012 \text { b) lists 'Episodes of going missing directly } \\
\text { following receipt of texts or calls' as an indicator } \\
\text { of Child Sexual Exploitation. Practical guidance to } \\
\text { reduce the potential for sexual exploitation } \\
\text { includes staff monitoring children outside the } \\
\text { home via contact by phone or face-to face checks. }\end{array}$ \\
\hline Belfast HSC Trust & None & None \\
\hline Northern HSC Trust & None & None \\
\hline South Eastern HSC Trust & & $\begin{array}{l}\text { Staff policy providing summary of roles and } \\
\text { responsibilities in the use of mobile phone/devices. } \\
\text { Stipulates no personal patient data be recorded } \\
\text { without documented patient consent. Mainly refers } \\
\text { to health and safety; what to do if phone is lost or } \\
\text { stolen and tariff costs. }\end{array}$ \\
\hline Southern HSC Trust & None & \\
\hline Western HSC Trust & None & 'house rules'/'incentive scheme' rules. \\
\hline
\end{tabular}

While the study did not set out to examine the social networking practices of social workers, it is noteworthy that the issue emerged during interviews with care home managers. The extent 
and nature of personal information that the social worker or key worker makes available on their own lives, through social networking sites such as Facebook, at least deserves some consideration or tentative guidance. It would useful to know whether this presents any potential implications for the Code of Practice for Social Workers (NISCC: 5.8)

\section{Summary}

This is the first study to focus on the ways in which mobile phone technology impacts on contact, either to enhance its value for young people and parents, or to exacerbate (or attenuate) the difficulties that already beset more traditional forms of contact. Unlike other forms of communication which, because more visible, can perhaps be more easily managed, contact via mobile phone presents a particular set of challenges. These are common to carers or guardians of all children and young people, but are intensified for carers of children in care, because of their particular histories, past difficulties and disrupted family relationships.

In the three years since this research was first initiated, the speed and scale at which mobile phones and other forms of e-technology have progressed has been immense. The widened scope for accessing the internet through common devices like mobile phones has shone an intensive focus on 'e-safety' issues, such as those reported in the Safeguarding Report for Northern Ireland (SBNI, 2014). Concerns with protection of children from obvious sources of harm, such as grooming and sexual exploitation, should not overshadow the more 'mundane' risks or problems that can occur within the unsupervised and possibly submerged contacts with family and friends that mobile phones facilitate.

The major difficulties this research faced in accessing and recruiting the population of interest resulted in a significant delay in reporting, and a more modest study than that originally approved. However, the principal issues raised in this report regarding contact arrangements for children living in care remain as relevant in 2014 as they were in 2011. These are:

- The lack of discussion of mobile phone facilitated contact during LAC reviews unless the subject has already emerged as a difficult issue. It would be prudent to consider this type of contact, regardless of whether mobile phone use is a concern. This need not be an intensive enquiry, instead it could be viewed as a potential indicator preceding the more formal practice guidance (see Appendix Three for an example of such an enquiry).

- In the majority of cases, mobile phone contact with birth family contributes positively to the enhancement of family relationships.

- Mobile phones per se can provide a reassurance and comfort to children and young people in care by offering the knowledge that instant contact with family can be achieved, if necessary.

- The technological knowledge gap between carers and young people is a fact. Therefore, punitive responses to e-safety worries are counter-productive.

\section{Implications for policy and practice}

- The position of mobile phone facilitated contact (texting, phone calls and on-line access) as a statutory form of contact requires review. This applies to contact from birth family to child but also from social worker to child. 
- Foster carers need to be made aware of the dynamics of mobile phone contact (child-birth parent/birth parent-child) and guided in forward planning for such eventualities.

- The interpretation and implementation of delegated authority is inconsistent across Trust areas resulting in foster carers and care staff being unsure of what they can and cannot do. This includes issues of contact using, or facilitated through the use of, mobile phones. It includes decisions such as whether or not a child in their care can or cannot take part in a research study. This leads to confusion and contradictory practices and should be addressed.

- While the study did not set out to examine the social networking practices of social workers, the fact that it emerged during the course of the study suggests the issue at least deserves some consideration or tentative guidance.

\section{Implications for research and research governance}

- As a minimum data quality standard, SOSCARE data should be kept up to date to reflect the allocation of a child to a specific social worker and social work team.

- Research governance arrangements between Trust areas are too wide and diverse. Disparities on such a scale impede the conduct of research and the delivery of research findings.

- To secure a successful and timely research outcome, the importance of a 'research champion' with the authority and support to insist that specific research is a priority, cannot be underestimated. 
Mobile phones and contact arrangements for children living in care

\section{References}

Abeele, M.V., Antheunis, M.L. and Schouten, A.P. (2014) 'Me, myself and my mobile: A segmentation of youths based on their attitudes towards the mobile phone as a status instrument', Telematics and Informatics, 31, pp 194-208.

Ballantyne, N., Duncalf, Z. and Daly, E. (2010) 'Corporate Parenting in the Network Society', Journal of Technology in Human Services, 28:95, pp 95-107.

Beckett, H. (2011) 'Not a world away' The sexual exploitation of children and young people in Northern Ireland, Barnardo's Northern Ireland.

Beek, M. and Schofield, G. (2004) Providing a Secure Base in Long-Term Foster Care, London: BAAF.

Biehal, N. (2007) Reuniting Children with their Families: Reconsidering the Evidence on Timing, Contact and Outcomes, British Journal of Social Work. 37, 807-823.

Blair, B.L. and Fletcher, A.C. (2011) 'The only 13-year-old on planet earth without a cell phone', meanings of cell phones in early adolescents' everyday lives, Journal of Adolescent Research, 26 (2), pp 155-177.

Bond, E. and Agnew, S. (2014) On-line abuse study, University Campus Suffolk and Marie Collins Foundation. http://www.ucs.ac.uk/About/News/2014/Childrens-WorkforceFindings.pdf

Campbell, S.W., Park, Y.J., (2008) 'Social implications of mobile telephony: the rise of personal communication society', Sociology Compass, 2, pp 281-371.

Caronia, L. and Caron, A.H. (2004) 'Constructing a specific culture: young people's use of the mobile phone as a social performance', Convergence: The International Journal of Research into New Media Technologies, 10, pp 28-61.

Castells, M., Fernandez-Ardevol, M., Linchuan Qiu, J., Sey, A., (2007) Mobile Communication and Society: A Global Perspective, Cambridge: MIT Press.

Christensen, T. (2009) 'Connected presence' in distributed family life', New Media \& Society, $11, \mathrm{pp} 433-451$.

Department for Health, Social Services and Public Safety (2010) Guidance on delegated authority to Foster Carers in Northern Ireland, Circular CCPD 01/10, Belfast: DHSSPS.

Department for Health, Social Services and Public Safety (2006) Our Children and Young People - Our Shared Responsibility, Inspection of Child Protection Services in Northern Ireland, Social Services Inspectorate, Overview Report, December 2006.

Fursland, E. (2010a) (updated in 2013) Facing up to Facebook, London: British Association for Adoption and Fostering.

Fursland, E. (2010b) Social networking and contact: How social workers can help adoptive families, London: British Association for Adoption and Fostering.

Fursland, E. (2011) Foster Care and Social Networking, London: British Association for Adoption and Fostering. 
Mobile phones and contact arrangements for children living in care

Health and Social Care Board (2012a) Practice Guidance on Assessing and Planning Contact for Looked-after Children, December 2012.

Health and Social Care Board (2012b) Regional Residential Childcare Policies, February 2012.

Little, M. Kohm, A. Thompson, R. (2005) 'The impact of residential placement on child development: research and policy implications', International Journal of Social Welfare, 14, 200-209.

Livingston, S. and Brake, D. (2010) 'On the rapid rise of social networking sites: New findings and policy implications', Children and Society, 24, 1, 75-83.

Livingston, S. and Haddon, L. (2009) EU kids online: Final report, London: EU Kids Online.

Livingston, S. and Helsper, E. (2007) 'Taking risks when communicating on the Internet: The role of offline social-psychological factors in young people's vulnerability to online risks', Information, Communication and Society, 10, 5, pp 619-643.

Macaskill, C. (2002) Safe Contact? Children in Permanent Placement and Contact with their Birth Relatives, Lyme Regis: Russell House Publishing.

Macdonald, G., Millen, S., McCann, M., Roscoe, H. and Ewart-Boyle, S. (2012) Therapeutic approaches to social work in residential child care settings, Children's and Families' Services Report 58, Belfast: Queen's University Belfast and Department for Health, Social Services and Public Safety.

MacDonald, M. and McSherry, D. (2013) 'Constrained adoptive parenthood and family transition: adopters' experience of unplanned birth family contact in adolescence', Child and Family Social Work, 18, pp 87-96.

Moyers, S. Farmer, E. Lipscombe, J. (2006) 'Contact with Family Members and its Impact on Adolescents and Their Foster Placements', British Journal of Social Work, 36, 4, pp 541559.

Mullan, C. McAlister, S. Rollock, F. Fitzsimons, L. (2007) "'Care Just Changes Your Life": Factors Impacting upon the Mental Health of Children and Young People with Experiences of Care in Northern Ireland', Child Care in Practice, 13, 4, 417 - 434.

Neil, E. Beek, M, Schofield, G. (2003) 'Thinking about and Managing Contact in Permanent Placements: The Differences and Similarities between Adoptive Parents and Foster Carers', Clinical Child Psychology and Psychiatry, 8, 401.

Neil, E. Howe, D. (Eds.) (2004) Contact in adoption and permanent foster care: Research, theory and practice, London: British Association for Adoption and Fostering.

Northern Ireland Social Care Council, Code of Practice for Social Workers, Belfast.

Ofcom (2013) Children and Parents: Media Use and Attitudes Report, published 3 October 2013. $\quad$ http://stakeholders.ofcom.org.uk/binaries/research/media-literacy/october2013/research07Oct2013.pdf 
Mobile phones and contact arrangements for children living in care

Quinton, D. Rushton, A. Dance, C. Mayes, D. (1997) 'Contact between Children Placed away from Home and their Birth Parents: Research Issues and Evidence', Clinical Child Psychology and Psychiatry, 2, 3, 393-413.

Regulation and Quality Improvement Authority (2013) Review of Statutory Fostering Services, Overview Report, December 2013.2 Available at: http://www.rqia.org.uk/publications/rqia_reviews.cfm

Richie, J. and Lewis, J. (Editors) (2003) Qualitative Research Practice, London: Sage.

Safeguarding Board for Northern Ireland (2014) An exploration of e-safety messages to young people, parents and practitioners in Northern Ireland, prepared by the National Children's Bureau for the Safeguarding Board for Northern Ireland.

Scottish Government (2008) These are our Bairns: A guide for community planning partnerships on being a good corporate parent, Edinburgh: Scottish Government.

Sinclair, I. (2005) Fostering Now: Messages from Research, London: Jessica Kingsley Publishers.

Taylor, B. and McQuillan, K. (2014) 'Perspectives of Foster Parents and Social Workers on Foster Placement Disruption', Child Care in Practice, Published on-line $10^{\text {th }}$ January 2014, DOI: 10.1080/13575279.2013.859567

United Nations Convention on the Rights of the Child (1989)

Valkenburg, P. and Peter, J. (2007)' Internet communication and its relationship to well-being: Identifying some underlying mechanisms', Media Psychology, 9, 1, pp 43-58.

Walsh, S.P., White, K.M. and Young, R.M. (2009) 'The phone connection: a qualitative exploration of how belongingness and social identification relate to mobile phone use among Australian youth, Journal of Community \& Applied Social Psychology, 19, pp 225240.

Weisskirch, R. (2011) 'No Crossed Wires: Cell Phone Communication in Parent-Adolescent Relationships', Cyberpsychology, Behavior and Social Networking, Vol 78, Number 7-8, pp 447-451.

Wilson, K., Sinclair, I., Taylor, C. Pithouse, A. and Sellick, C. (2004) Fostering Success: An Exploration of the Research Literature in Foster Care London: Social Care Institute for Excellence. 
Mobile phones and contact arrangements for children living in care 
Mobile phones and contact arrangements for children living in care

\section{APPENDIX ONE}

\section{Difficulties encountered/lessons learned}

The research protocol went through 8 versions prior to receiving overall ethical approval from the Office for Research Ethics Committees Northern Ireland (ORECNI) on $23^{\text {rd }}$ February 2011. The decision was subject to the approval of each Trust area. Soon after the research began, individual Trusts placed further stipulations to this version, with each amendment requiring a re-submission to ORECNI for approval. Eventually, version 12 of the research protocol received overall ethical approval from ORECNI on 19 April 2012 - more than a year after the OREC approval was originally granted.

The final protocol amendments resulted in additional layers of bureaucracy which, from the research perspective, made the full completion of the study almost impossible.

ORECNI comes under the Business Services Organisation which was established on 1 April 2009 under the Health and Social Care (Reform) Act (NI) 2009 as part of the second phase of the Reform of Public Administration (RPA). The purpose of the RPA was to review Northern Ireland's system of public administration with a view to putting in place modern, accountable and effective arrangements for public service delivery in Northern Ireland. The stated mission of ORECNI is to protect the rights, dignity and welfare of research participants within the HSC system/NHS, and to protect the rights of researchers to perform ethical research and legitimate investigation (see http://www.hscbusiness.hscni.net/services/orecni.htm). ORECNI also work closely with their counterparts in England, Wales and Scotland to maintain the established UKwide framework for ethical review of research.

Ethical approval from ORECNI is only received once their robust research ethics review process has been completely satisfied. Their high-level standards mean approval is viewed as the 'gold standard' within the research community and beyond. Continuous amendment and challenges by individual Trusts to ORECNI approved practices, implies both a lack of faith in ORECNI's judgement and opposition to ORECNI's authority. The implications of this situation will be discussed in more detail in the aforementioned follow-up report.

The main impediments are summarised below:

\section{Delegated authority}

Implementation of the regulations relating to delegated authority was inconsistently applied across Trust areas. This meant there was disagreement between Trusts on whether foster carers could assume responsibility for passing on the questionnaire to the young people in their charge.

This was followed by further disagreement between Trust areas on whether residential care workers and the child's social worker could assume responsibility for passing on the study materials.

\section{Recruitment of foster carers}

The TCs within each Trust were tasked with identifying foster carers with children aged 10 and over. SOSCARE records were used to identify the population of interest. Once identified, the TC would forward the information packs to the relevant address. The SOSCARE records 
proved to be less accurate than anticipated. This was complicated further by staff changes, staff sick leave and relocation of premises. The distribution of questionnaires through TCs yielded a very low response rate (76/841) and resulted in serious delay.

Given the difficulties in distributing the material, it was not though prudent to ask TCs to send out reminder letters. In order to increase the number of responses from foster carers, the Fostering Network was approached for assistance. The Fostering Network agreed to distribute the follow-up reminder letter, together with study information, pre-paid envelope and cover note inviting carers to take part. The questionnaire was also made available on-line. This increased the total number of responses received to 128 .

\section{Recruitment of children and young people living in foster care}

TCs also had responsibility for identifying children living in foster care aged 10-16 and those aged 17 years and over using SOSCARE data. This entailed identifying the senior social worker attached to the child/young person and forwarding the information to the senior social worker who would then pass on the information to the child/young person in their care. The task of matching up senior social workers and young people in care turned out to be an onerous job, adding to the existing heavy workloads of TCs.

When the senior social worker received the information packs, it was their responsibility to initiate the consent process by assessing each individual's 'capacity to consent'. The 'capacity to consent' process involved three steps:

1. Determine the child's capacity to give their consent against cognitive, social and emotional development, including understanding their right to participate or withdraw from the research. If the social worker does not think the young person is capable of understanding these issues, they should not be given access to the recruitment materials.

2. Assess if it is an appropriate time for the child/young person to take part in the research. If the senior social worker assesses that participation would cause disruption to their placement, they should not give the young person access to the recruitment materials.

3. If steps one and two are favourable, the senior social worker seeks consent from a birth parent or relative with parental responsibility (where contact with a birth parent or relative with parental responsibility is permitted in the care plan) for those aged 10-16, before giving the young person access to the research recruitment materials. If a birth parent or relative with parental responsibility is not accessible, it is the sole responsibility of the senior social worker to act as guardian in the consent process. For young people aged 17 and over, birth parent assent is requested.

Once a young person had been assessed at all three stages of the protocol as suitable to take part in the research, the senior social worker was to pass on the study materials to that young person's case social worker, who would give the young person the study pack and postal questionnaire at their next statutory meeting.

\section{Recruitment of children and young people living in residential care}

The TC for each Trust used SOSCARE data to identify children and young people living in residential care homes between the ages of 10 and 16 years and those aged 17 years and over. Responsibility was then passed to the senior social worker to initiate the consent process by 
assessing each individual's capacity to consent, as detailed above. If consent was approved, the study details were passed to the case social worker to distribute to the young person.

This placed a heavy burden on senior social workers and case social workers who were already dealing with complicated cases. It effectively left the research process vulnerable to priority setting by social workers. In addition, the extra layers of red tape meant a heavy reliance on clear lines of communication between each tier of administration. This was not always evident, as one key informant explained:

All these brown envelopes landed on our desk and nobody knew what they were and nobody knew where they came from.

The distribution of questionnaires, through teams of social workers, to children and young people in foster and residential care also resulted in extremely poor response rates and serious delay.

\section{Project re-launch}

In October 2012, the project was re-launched with a new strategy for distributing and collecting questionnaires to young people in residential and foster care.

To circumvent the extra layers of administration, the project researchers planned to visit residential children's homes, in the first instance, to deliver questionnaires to young people (aged 13-18) in person. However, the major problem of gaining birth parent consent, which the re-launch was attempting to resolve, became an obstacle for a second time. The Belfast Trust were insistent that foster carers and residential home staff could not be responsible for deciding whether a child in their care had the capacity to consent or not, and that researchers would have to seek birth parents' permission to ask the child whether they would mind completing the questionnaire.

Given the desire to complete the project, a pragmatic decision was made to concentrate on reaching young people aged 16 and over, whose capacity to consent did not have to be assessed by a carer or parent. However, this required honorary contracts and Access NI checks for the research team which would be visiting Trust properties. This is, by nature, a complicated and time consuming process which was made more difficult because of the time lag between the official launch and the re-launch date. For example, one Trust (Western) had recorded the project as closed.

The TCs in each Trust were required to sign the honorary contract applications before these could be processed. However, locating the TCs proved difficult as some had changed jobs or retired, with new TCs appointed in their place.

Clearance procedures operated by individual Trusts were inconsistently applied as each Trust had different requirements. For instance, some members of the research team already had current Access NI authorisation which was accepted as appropriate by some Trusts but not by others.

March 2013 (five months after the re-launch):

Belfast Trust - we were granted permission from the Belfast Trust to engage with care home managers regarding completion of the questionnaires by young people in their care. 
Mobile phones and contact arrangements for children living in care

\section{April 2013 (six months after the re-launch):}

Northern Trust - three of the four member research team had received honorary contracts. However, the TC for the project had been replaced and the new appointee did not know anything about the project.

Western Trust - no honorary contracts had been received and the TC was on sick leave. No one else knew anything about the project.

South Eastern Trust - the TC could not be contacted as emails and phone calls remained unanswered. A new TC was appointed.

Southern Trust - the TC was not contactable and we were unable to ascertain whether a new TC had been appointed.

\section{June 2013 (seven months after the re-launch):}

Belfast Trust agreed to post out information packs to all eligible young people in foster care. This helped increase the response rate of young people in foster care slightly.

\section{Lessons learned}

One of the main stumbling blocks was the inconsistent implementation and regulation of delegated authority. There was no agreement between Trusts on whether foster carers, social workers and residential staff had authorisation to decide whether a child in their care had the capacity to consent or not. This was a key driver in having the distribution of the research instrument (questionnaire) delegated to more than one tier of administration.

The TCs were central to the selection of children and young people for this study and social workers were central to the 'capacity to consent' protocol. This meant a heavy reliance on the good will of people, who already had heavy workloads, and clear communication between people who were separated from the central research process by layers of organisation.

The SOSCARE data formed an important part of the sampling frame. There had been an expectation that this data would be accurate and up-to-date. On reflection, the condition of this data should have been examined prior to the study's commencement.

A very important message to emerge from this experience is the significance of having a 'research champion' within each Trust area that has both the authority and the support network to insist that particular research is a priority. 
Mobile phones and contact arrangements for children living in care

\section{APPENDIX TWO}

Table 9: Data Sources

\begin{tabular}{|c|c|c|c|c|c|}
\hline & Informant category & Type of data & $\begin{array}{l}\text { Achieved } \\
\text { (n) }\end{array}$ & $\begin{array}{c}\text { Baseline } \\
\text { (n) }\end{array}$ & $\begin{array}{l}\text { Response } \\
\text { rate }\end{array}$ \\
\hline STAGE & \multicolumn{5}{|c|}{ PHASE ONE } \\
\hline 1 & $\begin{array}{l}\text { Senior staff with } \\
\text { responsibility for regional } \\
\text { policy \& governance \& } \\
\text { Inspection } \\
\text { Government Departments } \\
\text { Boards/Trusts/RQIA }\end{array}$ & $\begin{array}{ll}\text { - } & \text { semi- } \\
& \text { structured } \\
& \text { interview } \\
\text { - } & \text { documentary } \\
& \text { evidence }\end{array}$ & 8 & 25 & $32 \%$ \\
\hline 2 & $\begin{array}{l}\text { Residential care home } \\
\text { managers }\end{array}$ & $\begin{array}{ll}\text { - } & \text { Structured } \\
\text { telephone } \\
\text { interviews } \\
\text { - } & \text { Background } \\
\text { information }\end{array}$ & 20 & 25 & $80 \%$ \\
\hline 3 & Foster carers & Questionnaire & 128 & 841 & $15.2 \%$ \\
\hline 4 & $\begin{array}{l}\text { Children in Foster Care } \\
10-12\end{array}$ & Questionnaire & \multirow{2}{*}{83} & \multirow{2}{*}{843} & \multirow{2}{*}{$9.8 \%$} \\
\hline 5 & $\begin{array}{l}\text { Young People in Foster Care } \\
13+\end{array}$ & Questionnaire & & & \\
\hline 6 & $\begin{array}{l}\text { Children in Residential care } \\
10-12\end{array}$ & Questionnaire & \multirow{2}{*}{25} & \multirow{2}{*}{276} & \multirow{2}{*}{$9.1 \%$} \\
\hline 7 & $\begin{array}{l}\text { Young people in Residential } \\
\text { care } 13+\end{array}$ & Questionnaire & & & \\
\hline STAGE & \multicolumn{5}{|c|}{ PHASE TWO } \\
\hline 1 & $\begin{array}{l}\text { Young people in Foster care } \\
13+\end{array}$ & Focus group & $\mathrm{X}$ & & \\
\hline 2 & $\begin{array}{l}\text { Young people in Residential } \\
\text { care } 13+\end{array}$ & Focus group & $\mathrm{X}$ & & \\
\hline 3 & $\begin{array}{l}\text { Young people in Foster care } \\
13+\end{array}$ & Interview & $\mathrm{X}$ & & \\
\hline 4 & $\begin{array}{l}\text { Young people in Residential } \\
\text { care } 13+\end{array}$ & Interview & $\mathrm{X}$ & & \\
\hline 5 & Birth parents & Interview & $X$ & & \\
\hline 6 & Foster carers & Focus group & $\mathrm{X}$ & & \\
\hline 7 & Foster Carers & Interview & $X$ & & \\
\hline
\end{tabular}




\section{APPENDIX THREE}

\section{TITLE}

In considering contact arrangements, have you taken into account:

\section{Mobile phone facilitated contact ${ }^{4}$ between:}

Young person and parent

Young person and any person who is not a parent but who shares

parental responsibility for the child

$\square$ yes $\square$ no

$\square$ yes $\square$ no

Young person and any relative, friend or other person connected to him/her

$\square$ yes $\square$ no

What are the existing arrangements (if known) for this contact, for example, does the parent/other person phone the child and/or does the child phone parent/other?

Is the child satisfied with existing arrangements?

$\square$ yes $\square$ no

Is the parent/relative/other satisfied with existing arrangements?

$\square$ yes $\square$ no

Is the carer satisfied with existing arrangements?

$\square$ yes $\square$ no

Is the Trust satisfied with existing arrangements?

$\square$ yes $\square$ no

\section{Any issues or concerns}

I/We agree that contact arrangements facilitated by mobile phone are satisfactory. I/we agree that these arrangements will be reviewed on (e.g. next Looked-after Child Review or alternative agreed date).

Young person

Parent/Guardian

Social Worker

Carer

Date:

4 This includes telephone calls, emails, texts, voice mail, Snapchat, Whatsapp, Instagram, Facebook, Twitter, Skype. This list will vary as new applications emerge. 